\title{
Equipe Multiprofissional de Cuidados Paliativos da Oncologia Pediátrica: Uma Revisão Sistemática
}

\author{
Thais Cibere Bezerra de Oliveira ${ }^{1}$; Thércia Lucena Grangeiro Maranhão² ; Marianna Leite Barroso $^{3}$
}

\begin{abstract}
Resumo: A presente pesquisa objetivou realizar uma revisão sistemática sobre o papel da equipe multiprofissional de cuidados paliativos em oncologia pediátrica nas bases de dados PePSIC, SciELO e BVS, dos últimos cinco anos (2012-2016), a coleta dos artigos ocorreu através da combinação de descritores. De modo geral, os resultados foram organizados em três categorias: 1) Repercussões do câncer infantil na vivência familiar; 2) Tipos de coping utilizados na hospitalização e; 3) Cuidados paliativos - experiência de pacientes, familiares e profissionais da equipe multiprofissional. Foi possível observar que a temática abordada nesse estudo ainda é insipiente na literatura e que a graduação não prepara os profissionais para a atuação em cuidados paliativos. O câncer provoca mudanças na dinâmica familiar exigindo troca de papéis assumidos na família. É reconhecida a importância da humanização, porém ainda existem inúmeras dificuldades para executá-la, além de ser possível observar que o câncer pediátrico mobiliza tanto o paciente quanto os familiares e profissionais a buscarem formas de enfrentar e ressignificar o sofrimento. Quanto ao psicólogo na equipe de cuidados paliativos percebe-se que é reconhecida a importância atuação visto que este é o profissional capacitado para ouvir e acolher o sofrimento de todos os envolvidos (paciente, familiar, profissionais) dando espaços a questões psicológicas e emocionais decorrentes do adoecimento e hospitalização.
\end{abstract}

Palavras-Chave: Cuidados Paliativos. Psicologia. Oncologia. Pediatria. Equipe Multiprofissional.

\section{Multiprofessional Pediatric Oncology Palliative Care Team: A Systematic Review}

\begin{abstract}
The present study aimed to perform a systematic review on the role of the multiprofessional team of palliative care in pediatric oncology in the databases PePSIC, SciELO and BVS, of the last five years (2012-2016), the collection of articles occurred through the combination of descriptors. In general, the results were organized into three categories: 1) Repercussions of childhood cancer in family life; 2) Types of coping used in hospitalization and; 3) Palliative care - experience of patients, families and professionals of the multiprofessional team. In general, the results were organized into three categories: 1) Repercussions of childhood cancer in family life; 2) Types of coping used in hospitalization; 3) Palliative care - experience of patients, families and professionals from the multiprofessional team. It was possible to observe that a thematic approach in this study is still insipient in the literature and that an undergraduate does not prepare the professionals for an actuation in palliative care. Cancer causes changes in the family dynamics requiring the exchange of assumed roles in the family. The importance of humanization is recognized, but there are still many difficulties to carry it out. It is also possible to observe that pediatric cancer mobilizes both the patient and family members and professionals to seek ways to face and reframe suffering. As for the psychologist in the palliative care team, it is noticed that the importance of acting is recognized since this is the professional who is able to listen and receive the suffering of all involved (patient, family, professionals) giving space to psychological and emotional issues arising from Illness and hospitalization.
\end{abstract}

Keywords: Palliative Care. Psychology. Oncology. Pediatrics. Multiprofessional team.

\footnotetext{
${ }^{1}$ Graduanda do curso de Psicologia do Centro Universitário Dr. Leão Sampaio, Juazeiro do Norte - CE. E-mail: thaisbezerra@ outlook.com ${ }^{2}$ Professora orientadora da Unileão, psicóloga, graduada pela Faculdade de Ciências Humanas de Recife - ESUDA, Especialista em Gestão do trabalho e da Educação na Saúde, pela Escola de Saúde Pública do Estado do Ceará. Pós-Graduanda do curso de Mestrado em Ciências da Saúde, pela Faculdade de Medicina do ABC, E-mail: thercia@leaosampaio.edu.br.

${ }^{3}$ Enfermeira. Mestranda em Saúde pública pela Universidade Tecnológica Intercontinental - UTIC/PY. E-mail: mariannaleite_@hotmail.com;
} 


\section{Introdução}

Os cuidados paliativos (CP) são uma nova forma de cuidados que, em essência, visam o alívio da dor e o controle dos sintomas dos pacientes cujas terapêuticas curativas já não são mais possíveis (DOMINGUES et al., 2013). É uma prática de cuidar que não visa a cura, sendo pautada em princípios que norteiam a atuação dos profissionais da equipe de CP (SIMONETTI, 2011).

O câncer está associado à grande número de morte ao longo da história. É uma doença que provoca alterações no corpo, no psicológico e nas relações sociais e familiares do indivíduo acometido, como também na família. É uma doença crônica e constantemente associada à morte, sendo altamente indicada aos CP (MACIEIRA, PALMA, 2011; ROLIM, 2015; GURGEL, LAGE, 2013).

Os CP exigem um trabalho em equipe que possa possibilitar a vivência do sujeito como um ser global que necessita ser enxergado em todos os seus aspectos - biológico, psicológico, social e espiritual. Quanto ao papel do psicólogo, é cada vez mais indispensável, ao passo que este possibilita a expressão do sujeito para além da sua doença, disponibilizando espaço para subjetividade (BRITTO, 2010; DOMINGUES et al., 2013).

O presente estudo trata-se de uma revisão sistemática acerca das equipes multiprofissionais de cuidados paliativos (CP) no setor da oncologia pediátrica, abordando as formas de trabalho dessa equipe que tem uma visão diferenciada do sujeito como ser biopsicossocioespiritual. Bem como os impactos psicossociais do câncer infantil, questões relativas ao luto e CP na percepção dos familiares e equipe multiprofissional.

Tendo em vista o que foi abordado, o presente trabalho apresenta como objetivo geral realizar uma revisão sistemática sobre o papel da equipe multiprofissional de cuidados paliativos da oncologia pediátrica. E como objetivos específicos: a) Realizar uma busca de artigos sobre o papel da equipe multiprofissional de cuidados paliativos em oncologia pediátrica nas bases de dados PePSIC (Periódicos Eletrônicos em Psicologia), SciELO (Scientific Eletronic Library Online) e BVS (Biblioteca Virtual de Saúde); b) Promover uma categorização dos artigos de acordo com as temáticas, metodologias utilizadas e os resultados alcançados; c) Compreender as questões mais debatidas nos artigos que tratam da equipe de cuidados 
paliativos e; d) Identificar a relevância do trabalho da equipe multiprofissional nos cuidados paliativos.

Este estudo partiu da curiosidade em entender como a equipe multiprofissional pode colaborar para aliviar os sofrimentos dos pacientes que já se encontram fora das possibilidades de cura. Além de contribuir para novas inquietações acerca da prática do profissional de psicologia nos CP, contribuindo dessa forma para realização de novas discussões sobre o tema. O interesse pela temática justifica-se pelo desejo de contribuir para uma prática mais consciente e responsável dos profissionais que atuam junto às famílias enlutadas pela eminente perda.

\section{Oncologia Pediátrica}

A palavra "câncer" se originou de Karkínos, expressão grega que quer dizer caranguejo. É utilizada para designar um conjunto de mais de cem doenças que apresentam como característica comum, o crescimento e desenvolvimento desordenado das células que tendem a atingir os tecidos vizinhos. Sua diferença é dada de acordo com o órgão que é afetado e o tipo de tumor que é originado. Em crianças os tumores mais frequentes são os que afetam os glóbulos brancos (leucemias), os linfomas e o Sistema Nervoso Central (INCA, 2011).

O câncer é uma doença crônica, não contagiosa e pode acometer pessoas nas mais diferentes faixas etárias, raças ou níveis socioeconômicos (ALCÂNTARA et al., 2013). Por ser uma doença crônica e que, frequentemente, é encarada como ameaça à vida, o câncer torna-se potencialmente indicada aos CP (GURGEL; LAGE, 2013).

O diagnóstico de câncer traz grandes inquietações, se constituindo em um evento traumático para a família e a pessoa acometida, necessitando assim de uma visão integral do sujeito e um trabalho em equipe visando o alívio dos sintomas, não apenas os físicos, mas também os psicológicos e emocionais (MACIEIRA; PALMA, 2011).

Quando recebe o diagnóstico de câncer torna-se inevitável afastar-se da escola, mas é sabido que ainda assim, a criança necessita desse processo de educação e desenvolvimento. No que diz respeito ao público infantil, escolas e hospitais dividem as responsabilidades para não deixar que a criança fique sem o acompanhamento escolar e não tenha que abrir mão do tratamento (ROLIM, 2015). A criança com doença crônica e que está em idade escolar entende 
a sua situação e a condição da doença dependendo da capacidade e compreensão que adquiriu (GOMES et al., 2013).

No Brasil, o câncer ainda está atrelado aos maiores índices de mortalidade. O desenvolvimento da ciência tem contribuído de forma significativa para elevar a quantidade de sobreviventes, além de buscar a melhoria da qualidade de vida dos pacientes e a diminuição dos impactos emocionais causados pelo diagnóstico e prognóstico (MACIEIRA; PALMA, 2011).

No setor da oncologia pediátrica, o vínculo se torna uma ferramenta dos profissionais de saúde para lidar com as crianças doentes e seus familiares. É um fator bastante importante para relação e mais fácil de ser estabelecido, tendo em vista a condição crônica do câncer e o fato da criança ser cativante, exigindo dos profissionais um cuidado e envolvimento maior (VIERO, 2014).

A oncologia pediátrica é uma área médica que exige dos profissionais uma qualificação e um comprometimento com o cuidado integral à criança e seus cuidadores. Requer da equipe de cuidados além de preparo técnico e terapêuticas específicas, empatia, ética profissional, disponibilidade para ouvir e sensibilidade para perceber as necessidades dos pacientes e acompanhantes. Envolve a combinação de conhecimentos técnicos, científicos e estratégias de humanização no cuidado, de forma que estes possibilitem uma escuta qualificada voltada para o sofrimento gerado pelo diagnóstico e implicações na rotina dos envolvidos (AMADOR et al., 2010).

A partir do que foi exposto, pode-se perceber que o trabalho em oncologia pediátrica envolve aspectos diferenciados, exigindo uma preparação e capacitação maior dos profissionais para lidar com as situações desencadeadas pelo diagnóstico até à morte do paciente, tendo em vista que o câncer é gerador de muitas mudanças na rotina do indivíduo e seus cuidadores, além de todas as implicações psicológicas emocionais e sociais que este diagnóstico acarreta na vivência de todos os que estão envolvidos no processo de cuidar. 


\section{Aspectos Psicossociais do Câncer}

Por ser rodeado de preconceito e tabus, o câncer ainda provoca bastante pavor, devido estar ao longo dos anos associado a grande sofrimento, dor e à morte (MACIEIRA; PALMA, 2011).

O câncer se configura como uma doença que afeta não apenas o corpo, mais também o psicológico, as relações familiares e sociais, qualidade de vida e a dinâmica familiar e de trabalho, envolvendo dessa forma aspectos biopsicossociais (MACIEIRA; PALMA, 2011).

No entendimento de Silva (2012), a doença adquire significado para o sujeito a partir da maneira como é consolidada em seu imaginário. Receber o diagnóstico de uma doença que ao longo da história ceifou muitas vidas e que está histórica e socialmente ligada a morte, provoca no paciente e naqueles que estão ao seu redor um turbilhão de sensações, sentimentos e emoções. Em concordância com essa ideia, Gomes et al. (2013), afirmam que os sentimentos de medo, insegurança e incerteza são mais acentuados quando há o diagnóstico de câncer infantil, visto que a criança ainda está no início da vida e poderá ter seus sonhos e desejos interrompidos.

Em acordo com a ideia de silva (2012), Macieira, Palma (2011) afirmam que mesmo com todos os avanços alcançados pela ciência tanto na terapêutica quanto nas formas de cuidar, o câncer ainda é uma doença que causa medo e temor frente ao diagnóstico, visto que ao longo dos anos foi marcada pelo estigma da dor, do sofrimento e da morte. E que nem os avanços tecnológicos afastaram de alguns pacientes e familiares a ideia de que o câncer é a ruptura dos planos e dos sonhos futuros.

Além de todas as implicações psicológicas e biológicas que ocorrem na vida da criança doente, a hospitalização representa uma mudança significativa em sua rotina e na rotina de seus familiares. A criança internada troca as cadeiras da sala de aula por leitos em enfermarias. Com a internação, a criança é impelida a trocar as atividades educacionais por protocolos médicos (ROLIM, 2015).

O câncer pediátrico é um acontecimento que produz severas modificações na dinâmica familiar, afetando profundamente as vivências familiares em esferas diversas (MENDESCASTILLO, BOUSSO, 2016). 
Na oncologia pediátrica, a morte é um aspecto bastante presente e não há como escondêla, sendo necessário aos profissionais mais que o aparato tecnológico, é preciso sensibilidade e empatia pelo sofrimento do outro, além de abertura para o diálogo e respeito à dignidade e a liberdade humana (SOUSA et al., 2015).

Tendo em vista o que foi discutido, pode inferir-se a necessidade de um trabalho em equipe para a família e a criança, onde as mesmas possam ser orientadas e entendidas em seus medos, anseios, angústias e todos os sentimentos que são causados pelo diagnóstico de câncer. Além de trabalhar as implicações que a doença provoca, uma vez que a vida da criança e de seus familiares/cuidadores são altamente afetadas em decorrência dessa nova rotina e das perdas, tanto reais quanto simbólicas, já que o câncer implica muitos impactos e mudanças.

\section{A família e o luto}

O luto pela perda de um ente querido é uma experiência subjetiva vivida de formas e intensidades diferentes, e dependerá da quantidade e da qualidade do afeto investido naquele que morreu. A dor provocada pela perda de alguém querido tomam proporções significativas nas esferas emocionais e psíquicas de todos os envolvidos no processo (ALMEIDA et al., 2015).

Mesmo diante de todos os avanços alcançados pela medicina e pela ciência, a morte ainda é encarada como algo extremamente abominável, aterrorizante e que o ser humano não consegue aceitar, sendo desta forma pouco falada e pouco debatida (DOMINGUES et al., 2013).

Com os avanços tecnológicos e científicos a medicina vem buscando maneiras de prolongar a vida e, consequentemente, adiar a morte (MELO; CAPONERO, 2011). Na mesma linha de raciocínio, Kübler-Ross (2008), afirma que quanto mais a ciência se desenvolve, mais é frequente ter medo e negar a morte.

As crianças em processo de hospitalização apresentam uma habilidade precoce na percepção da morte. Vivenciar esse processo de adoecimento, tratamento e evolução para a fase terminal da doença influencia de forma significativa a concepção de morte que a criança irá 
apresentar. A criança doente é mais sensível para perceber as mudanças que ocorrem em seu corpo e em seu ambiente (CHIATONNE, 2012).

Na concepção de Arruda-Colli (2015), a morte de um filho configura-se como um evento de grande impacto para os familiares ao passo que se apresenta como a ruptura prematura da vida da criança e dos sonhos que os pais haviam planejado, além do fato de romper também com a continuidade biológica da família.

Ainda é pouco abordado a concepção dos avós sobre o câncer pediátrico (MENDESCASTILLO, BOUSSO, 2016). Mas existem pesquisas que indicam que para os avós, a morte de um neto é gerador de um impacto psicológico e emocional considerável, ao passo que conduz para uma inversão na ordem cronológica na qual se esperam que os mais velhos morram primeiro (ARRUDA-COLLI, 2015; MENDES-CASTILLO, BOUSSO, 2016).

Diante do diagnóstico de um tumor maligno o paciente e seus familiares passam por um processo de luto, no qual estão inclusas cinco fases: negação e isolamento, raiva, barganha, depressão e aceitação. Pontuando que não necessariamente todos os pacientes passarão por todas as fases e nem se dará em ordem cronológica. Cada paciente e familiar passará por essas fases de um forma própria e em ordem diferente (KÜBLER-ROSS, 2008).

A fase denominada de "negação e isolamento" é entendida como uma medida radical do paciente após receber uma notícia inesperada no qual não quer acreditar que isso está acontecendo, além de ser uma defesa do paciente e dos familiares frente a essa nova realidade. O estágio "raiva" surge quando o paciente já não consegue mais manter-se no isolamento e na negação e é movido por sentimentos de raiva e de barganha. A "barganha" é o momento no qual o sujeito tenta negociar, normalmente com Deus, a fim de conseguir mudar a situação difícil que está sendo vivenciada. É uma fase de curta duração na qual é comum o aparecimento de promessas. É uma tentativa, do paciente e dos familiares, de tentar adiar o fim que é inevitável e irremediável, prometendo que se o caso for revertido, o paciente apresentará boas condutas e mudanças de comportamento (KÜBLER-ROSS, 2008).

No estágio denominado de "depressão" o paciente já não tem mais como negar a presença da doença devido aos procedimentos necessários e as internações cada vez mais frequentes. E, ao invés de apresentar comportamentos de raiva, começam a surgir os sentimentos de perdas simbólicas e reais. É válido ressaltar que essa depressão não diz respeito ao transtorno depressivo e se faz necessária para que o sujeito possa chegar ao estágio de 
“aceitação" que se configura como o momento em que o sujeito já conseguiu elaborar as perdas (lugares, familiares, objetos) e se apresenta tranquilo para encarar a morte. Nesse momento o paciente mostra-se bastante cansado e frágil, tendo consciência de que não adianta mais lutar contra a morte (KÜBLER-ROSS, 2008).

De acordo com Almeida et al. (2015), os estilos de enfrentamento utilizados para superar momentos difíceis no decorrer da vida sofrem forte influência da forma de apego que é desenvolvida ao longo das relações estabelecidas.

Em síntese, a família vivencia muitas perdas ao longo do diagnóstico, tratamento e evolução para morte de um membro da família, sejam elas reais ou simbólicas, perda de lugares, de pessoas, de espaço ocupados, entre outros. Quanto às fases do luto, são essenciais para que os sujeitos possam chegar à aceitação, à ressignificação, atribuindo outro sentido a experiência dolorosa. E para conseguir lidar com esse período de sofrimento, utilizam-se de algumas formas de enfrentamento que se alteram de acordo com as experiências vivenciadas anteriormente.

\section{Cuidados Paliativos na Perspectiva da Família e da Equipe Multiprofissional}

Quando se trata de CP, é imprescindível falar da filosofia dos Hospices. Derivada do latim hospes, que significa estranho, a palavra hospice atualmente é utilizada para denominar o local que acolhe e cuida de pessoas que estão em um estágio em que a doença é incurável e que estão em processo de terminalidade (SANTOS, 2011).

Falar de Hospice e de CP remete ao trabalho desenvolvido por Cicely Saunders que, assim como Elisabeth Kübler-Ross, é um dos grandes nomes no que diz respeito aos debates sobre morte, morrer e cuidados paliativos. Durante anos, Cicely Saunders consolidou os princípios dos modernos hospices. Além de disponibilizar tempo para ouvir as necessidades sociais, espirituais e emocionais dos pacientes, ela buscou ensinar para os demais aquilo que aprendia na vivência com os moribundos (SANTOS, 2011).

A expressão "cuidados paliativos" é empregada para denominar um trabalho em equipe multiprofissional aos indivíduos cujas possibilidades curativas já não surtem os resultados que se almejam. É utilizado para designar proteção para os indivíduos cuja cura médica já não acolhe mais (HERMES; LAMARCA, 2013). 
No que diz respeito aos cuidados paliativos no Brasil, sua história é recente, tendo seu início por volta de 1980. No ano de 1997, a Associação Brasileira de Cuidados Paliativos (ABCP) foi criada, sendo composta por um grupo de profissionais que manifestou forte interesse na temática e propuseram práticas para divulgação dessa nova filosofia de cuidar no Brasil. E em 2005 mais um passo foi dado com a criação da ANCP - Academia Nacional de Cuidados Paliativos (HERMES; LAMARCA, 2013).

A medicina paliativa prega que mesmo quando não há o que fazer para devolver a saúde ou promover a cura do paciente, ainda tem-se muito o que fazer por aquele paciente no sentido de possibilitar o desenvolvimento de recursos de enfrentamento diante do processo de adoecimento, resgatando a autoestima e estabilidade, sendo dessa forma, essencial a participação do psicólogo em uma equipe de CP (SIMONETTI, 2011).

Domingues et al. (2013) em conformidade com a ideia acima, defende que ainda que não existam possibilidades curativas, o paciente deve ser cuidado e respeitado, tendo em vista a sua dimensão humana e subjetiva. É preciso levar em consideração os aspectos sociais espirituais e psicológicos, visto que uma doença terminal traz implicações biopsicossociais para a vida do indivíduo e também para os profissionais da equipe de saúde e familiares, pois torna consciente o processo de finitude da vida. Em consonância com essa ideia Hermes, Lamarca (2013), afirmam que o paciente não é apenas um aspecto (biológico, social, espiritual, psicológico) e por isso deve ser cuidado e atendido em todos os seus aspectos, visto que se um não funcionar os demais são afetados.

Para o trabalho em $\mathrm{CP}$, os profissionais de saúde necessitam de uma formação acadêmica que abranja essa temática (GUIMARÃES et al., 2016). Nenhuma ciência ou especialidade separadamente consegue abranger a complexidade da existência humana, por isso a necessidade de uma equipe multiprofissional para lidar com todas as dimensões e formas de cuidar, buscando a redução do sofrimento e da dor e consequentemente a qualidade de vida do sujeito e de seus familiares (MACIEIRA; PALMA, 2011).

Encarar um paciente com um tumor maligno é algo extremamente desconfortante para os profissionais, ao passo que isso conduz para a própria finitude. O diagnóstico de câncer já coloca o paciente diante de sua morte e cabe ao profissional estabelecer uma relação de confiança, no qual seja explicado que estará à disposição do paciente e seus familiares no 
processo de recuperação e quando não for mais possível curar, estará ao lado aliviando as dores e fazendo o que pode ser feito para melhorar a qualidade de vida (KÜBLER-ROSS, 2008).

Os CP apresentam princípios norteadores para a atuação dos profissionais, são eles: promoção do alívio de dor e sintomas encarados pelo paciente e seus familiares como sendo estressantes; reafirmação da vida e encara a morte como sendo natural para a vivência humana; não visa nem adiar nem aproximar a morte; mas favorece seu acontecimento no tempo certo; integração de perspectivas sociais, psicológicas e espirituais ao cuidado; oferecimento de suporte para que o paciente possa viver da forma mais ativa possível até a morte; oferta suporte para que os familiares sintam-se acolhidos e amparados no decorrer de todo o processo, devendo ser iniciado o mais breve possível (MACIEL, 2008).

Nos CP, o foco não é a doença, mas sim o sujeito que deve ser respeitado, informado e consciente de todo o processo que ocorre. É um fazer multiprofissional que preconiza individualidade na atenção ao doente e seus familiares, buscando erradicar o sofrimento (MACIEL, 2008).

Em suma, ainda é pouco falado dos cuidados paliativos na concepção dos familiares, mas se configura como uma forma de cuidado importante ao passo que produz qualidade de vida para a família e para o paciente. Na concepção dos profissionais, a experiência em cuidados paliativos é diferenciada e demanda maior cuidado e preparação técnica e humanitária para interagir de forma satisfatória com aqueles que necessitam de cuidados. E os cuidados paliativos prezam pela qualidade de vida e de morte do paciente, sendo baseados em princípios.

\section{Psicologia Hospitalar}

No Brasil, a psicologia hospitalar começou a se consolidar no mesmo período em que a profissão foi regulamentada no país, na década de 60. A psicologia hospitalar teve como grande precursora a psicóloga Mathilde Neder, que escutava os doentes hospitalizados articulando sensibilidade e técnica, pautando sua atuação nos princípios da dignidade humana (TOREZAN et al., 2013).

Apenas por volta do ano de 1968 que as primeiras disciplinas da saúde foram incluídas nas ementas dos cursos de Psicologia, incialmente apenas na Universidade de São Paulo e por 
volta 1995, as instituições de saúde tornaram-se o segundo maior campo de inserção dos profissionais de psicologia. Atualmente, no Brasil, a psicologia hospitalar é uma especialidade que encontra-se em expressivo crescimento e desenvolvimento, exigindo dos profissionais competências e habilidades específicas (TOREZAN et al., 2013).

A psicologia hospitalar é um campo de atuação que pode ser definido como um espaço de entendimento dos aspectos psicológicos que estão envolvidos no processo do adoecimento. É um espaço que busca auxiliar aquele que sofre a elaborar simbolicamente o adoecimento através da palavra e do ouvir. E apresenta como objetivo primordial acessar a subjetividade dos indivíduos que se encontram em processo de hospitalização (SIMONETTI, 2011).

O processo de terminalidade é um grande gerador de sofrimento, haja visto que o sujeito sente-se como se estivesse perdendo o controle da própria vida e do próprio corpo. Assim, a criação de um espaço para dar lugar as questões psicológicas, aos medos e angustias, onde o sujeito possa falar e se expressar sem restrições e sem julgamentos é de suma importância para a construção do cuidado, sendo esse o campo da psicologia hospitalar (FERREIRA; RAMINELLI, 2012).

Na perspectiva de Angerami-Camon (2012), a hospitalização, além de um processo de institucionalização do sujeito, é um período de mudanças significativas na vida do doente e seus familiares. Partindo dessa ideia, o autor elenca como objetivo da psicologia hospitalar a diminuição do sofrimento causado pela hospitalização, principalmente os efeitos emocionais e psicológicos. E Quintana et al. (2011), afirmam que a hospitalização é grande gerador de implicações subjetivas nos indivíduos doentes e seus familiares.

Por se tratar de criança, a hospitalização se torna um processo mais delicado, visto que além das alterações na rotina e do afastamento da escola, poderá também acarretar em alterações no desenvolvimento da criança (GOMES; FERNANDES; NÓBREGA, 2016).

No que diz respeito as diversas patologias encontradas no hospital, Simonetti (2011) considera que qualquer doença é repleta de subjetividade e aspectos psicológicos, sendo dessa maneira possível o trabalho da psicologia hospitalar. Britto (2010) e Sousa et al. (2015) acrescentam que a doença e morte são eventos próprios da natureza do ser humano e que apesar de ser algo intrínseco a vivência humana, é fortemente observado que as pessoas não desejam tornar consciente e ainda a vivencia como "acidente de percurso". 
Em suma, a psicologia hospitalar é uma área em expressivo crescimento e se configura como um espaço destinado para trabalhar os sofrimentos daqueles que necessitam de cuidados. É um espaço em que o sujeito é acolhido e escutado em suas dificuldades e seu discurso não é julgado. No que diz respeito à hospitalização, é um processo doloroso em que o sujeito e seus familiares precisam se adaptar à nova rotina, sendo necessário o trabalho da psicologia hospitalar que pode atuar com pacientes com as mais diversas patologias.

\section{Psicólogo em Equipes de Cuidados Paliativos}

Devido ao choque ocasionado pelo diagnóstico, os familiares normalmente culpabilizam uns aos outros na tentativa de encontrar um responsável pelo adoecimento da criança. Nesse momento cabe uma intervenção psicológica, inicialmente com os pais, na tentativa de possibilitar o processo de elaboração do luto que está sendo vivenciado (BRITTO, 2010; FAGUNDES et al., 2015). Para Alcântara et al. (2013), quando a família recebe o diagnóstico de uma doença potencialmente fatal de um filho, é comum passarem por mudanças abruptas em sua rotina, sendo necessário a atuação da equipe multiprofissional no sentido de diminuir o desespero dos familiares e minimizar as fantasias que os pais tem de que são os culpados pelo adoecimento e sofrimento que acomete o filho.

A despersonalização do paciente é um aspecto bastante presente no âmbito hospitalar, na qual o sujeito deixa de ter um nome e uma história para ser reduzido ao leito, ao diagnóstico/patologia ou órgão do corpo acometido por uma determinada doença. Sendo decorrente do fato de que o uso da tecnologia vem favorecendo diagnósticos cada vez mais precisos, o que leva a uma cisão do homem que além de não abarcar toda a dimensão existencial do ser humano ainda o reduz à sintomas ou doença (ANGERAMI-CAMON, 2012).

O sofrimento do paciente e dos familiares demanda dos profissionais de saúde humanização e empatia na abordagem e no diálogo. Está diante de um paciente que apresenta uma doença que ameaça a continuidade da vida, ainda mais quando se trata de uma criança, provoca sentimentos de medo, desesperança e temor, visto que conduz aos que estão à sua volta a conscientização da fragilidade corpórea e todas as vulnerabilidades as quais o ser humano está exposto (PORTO; LUSTOSA, 2010). 
No contexto hospitalar é necessária a presença do profissional de psicologia, tendo em vista que seu trabalho possibilita espaço para a subjetividade, disponibilizando uma escuta especializada e a ressignificação do sofrimento (BRITTO, 2010). Santos e Sebastiani (2012) corroborando com a ideia, acrescenta que na classe hospitalar, o psicólogo é profissional que mais tem sensibilidade e preparação para ouvir empática e pacientemente àquele que sofre.

Domingues et al. (2013), afirmam que a presença do psicólogo torna-se cada vez mais necessária no contexto hospitalar, visto que é sensível para as questões que normalmente são esquecidas pelos demais profissionais. Tornando-se imprescindível ao psicólogo ter uma visão integral do sujeito, possibilitando a expressão de suas dores físicas e psicológicas, baseado na visão de sujeito para além do sintoma (MORAIS; CASTRO; SOUZA, 2012).

A inserção do psicólogo no âmbito dos CP foi evidenciado como grande avanço e de extrema importância para essa nova forma de cuidar, em especial no período de internação do sujeito (DOMINGUES et al.; 2013; SANTOS, MENEZES, GRADVHL 2013; FERREIRA, ROMINELLI, 2012).

No âmbito dos CP, a atuação do psicólogo não é no sentido de promover cura ou de devolver a saúde do paciente, mas a promoção da "boa morte", ou seja, promover ao paciente uma qualidade de vida enquanto se espera a morte. Vale ressaltar que "boa morte" refere-se ao respeito, cuidado e empatia pelo sofrimento do outro, refere-se à humanização do cuidado daqueles que estão fora das possibilidades curativas (PORTO; LUSTOSA, 2010).

$\mathrm{Na}$ equipe de $\mathrm{CP}$ composta pelos mais diversos profissionais, o psicólogo terá como possibilidades de atuação o trabalho junto ao paciente, familiar/cuidador e à própria equipe, trabalhando tanto de forma individual como coletivamente (DOMIGUES et al., 2013; SCHLIEMANN, 2011).

Schmidt, Gabarra, Gonçalves (2011), salienta que é frequente a mobilização dos profissionais de saúde frente à situações de morte iminente de pacientes em processo de hospitalização, sendo importante que ao psicólogo hospitalar expandir seu trabalho para essa classe. É cabível também a intervenção psicológica no sentido de auxiliar os profissionais na escolha dos melhores procedimentos e tratamentos tendo em vista as necessidades de cada paciente. Domingues et al. (2013) complementa a ideia afirmando que o psicólogo poderá intervir como mediador da relação entre o paciente e profissionais na tentativa de reduzir os 
conflitos, visto que no período de internação e de terminalidade há uma carga emocional expressiva de todos os envolvidos nesse processo.

No manejo com os familiares, o psicólogo poderá atuar no sentido de aliviar o sofrimento ocasionado pela modificação na rotina, visto que o câncer de um filho é encarado como um agente substancialmente estressor que produz impactos para a relação conjugal (RECH; SILVA; LOPES, 2013). Atuar na orientação dos familiares quanto a importância de se fazerem presentes no processo de cuidados paliativos e morte da criança (DOMINGUES et al., 2013). Ajudar a romper o silêncio e permitir falar sobre as implicações da doença e aspectos relacionados ao tratamento e promover um suporte emocional para prevenir desordens psíquicas que são geradoras de sofrimento e estresse (HERMES; LAMARCA, 2013).

Ainda no tocante ao trabalho com a família, Reigada et al. (2014) afirmam que o objetivo primordial é auxiliá-la a completar sua função de cuidadora, buscando torná-los participativos no processo de $\mathrm{CP}$ e colaborando para que o momento da perda seja vivenciado da forma mais saudável.

E no trabalho com o paciente, o psicólogo irá atuar para facilitar a elaboração do seu processo de luto diante da morte que está se aproximando, respeitando o tempo necessário para a aceitação do processo. $\mathrm{Na}$ busca da minimização do sofrimento, das angústias e medos, promovendo a melhora na qualidade de vida e tornando menos pesado essa nova realidade (REZENDE; GOMES; MACHADO, 2014). É propício também o trabalho junto ao paciente para o resgate da autonomia e autoestima que é assolada pelo processo de institucionalização (MORAIS; CASTRO; SOUZA, 2012).

Quando se trata de pacientes que tem o diagnóstico de uma doença que ameaça a vida, ou seja, uma doença potencialmente fatal, as emoções são intensamente modificadas. Diante disso, o psicólogo poderá atuar de várias formas atendendo o paciente, a família e os profissionais, avaliando as condições psíquicas para o enfrentamento do processo de adoecimento e de morte (SCHLIEMANN, 2011).

Para se aproximar da criança e estabelecer um vínculo de confiança, o psicólogo poderá se utilizar de algumas estratégias lúdicas, visto que estas se assemelham a rotina anterior à doença e internação. O brinquedo é uma ferramenta imprescindível para os atendimentos infantis porque através do brincar a criança vivencia, cria e recria sua realidade e seu cotidiano (ALCÂNTARA et al., 2013). 
Corroborando com a ideia acima, Britto (2010) e Freitas, Gonçalves, Morais (2016), afirmam que no trabalho com crianças torna necessária a utilização de intervenções mais lúdicas. É indispensável a presença de um espaço disponível para a brincadeira. É através do brincar que o psicólogo cria um ambiente propício para trabalhar com a criança, compreendendo os aspectos emocionais e psicológicos envolvidos no processo de adoecimento.

Bernardo (2011) ressalta a importância da arteterapia devido ao seu potencial significativo na promoção da qualidade de vida das crianças em processo de $\mathrm{CP}$, visto que a aplicação de recursos artísticos cria espaços para o estabelecimento do vínculo necessário à uma relação de confiança e facilita o direcionamento entre aspectos da personalidade humana. Além de facilitar para o desenvolvimento de potencialidades e a inserção de novas habilidades ao repertório comportamental do sujeito.

Nessa mesma linha de pensamento Sampaio, Sampaio (2011) ressaltam que a associação entre práticas musicais e saúde são percebidas há muito tempo. Nos CP a musicoterapia possibilita ao paciente e seus familiares reabilitar o contato consigo mesmo e com o mundo. Através das práticas musicais o sujeito poderá ressignificar seu sofrimento, atribuindo novos sentidos a sua vivência e seu processo de finitude.

Diante do exposto acima, pode-se perceber que o psicólogo poderá se utilizar de várias ferramentas para abordar e trabalhar com as crianças internadas, visto que através dessas ferramentas poderá construir uma relação e um cuidados com outras alternativas, além da fala e da escuta. Através de outras ferramentas o psicólogo poderá alcançar um cuidado mais efetivo, tendo em vista a necessidade de cada paciente e demanda na tentativa de colher o máximo de informações e poder contribuir da forma mais significativa para a vivência desse período de grandes dificuldades e de adaptação a essa nova realidade.

\section{Metodologia}

Este estudo propõe uma revisão sistemática da literatura dos últimos cinco anos, mais especificamente de 2012-2016. A revisão sistemática é uma espécie de investigação que tem foco em questões bem definidas, visando identificar, selecionar, sintetizar e avaliar as evidências relevantes disponíveis (GALVÃO; PEREIRA, 2014). Objetiva o levantamento, 
união e avaliação crítica da metodologia utilizada nas pesquisas e síntese dos principais resultados dos estudos selecionados. É sistematizado e busca resposta para uma pergunta norteadora da pesquisa que foi clara e delimitadamente elaborada (GOMES; CAMINHA, 2014).

Galvão e Pereira (2014) pressupõem métodos para a realização de uma revisão sistemática: (1) elaborar uma pregunta de pesquisa; (2) buscar na literatura matérias que contemplam o objeto em estudo; (3) selecionar os artigos; (4) extrair os resultados; (5) avaliar a qualidade metodológica; (6) analisar os dados (metassíntese); (7) avaliar a qualidade das evidências; e (8) escrever e publicar os resultados.

A pergunta de partida que foi utilizada no presente estudo foi: qual o papel da equipe multiprofissional de cuidados paliativos para promoção de uma qualidade de vida dos pacientes e seus familiares na oncologia pediátrica?

Para embasar o estudo, foram utilizados materiais que tratam da psicologia hospitalar e equipes multiprofissionais de cuidados paliativos no setor de oncologia pediátrica. Inicialmente os artigos foram selecionados pelos títulos e resumos que contivessem algum dos descritores: cuidados paliativos, psicologia, equipe multiprofissional, oncologia e pediatria. A escolha dos bancos de dados eletrônicos ocorreu tendo em vista que são os mais conhecidos e acessados no Brasil. As fontes de pesquisa utilizadas foram: BVS, Scielo e PePSIC, além de obras literárias impressas.

A primeira base de dados utilizada foi o PePSIC - Portal Periódicos Eletrônicos de Psicologia, é uma fonte da Biblioteca Virtual em Saúde - Psicologia da União LatinoAmericana de Entidades de Psicologia (BVS-Psi ULAPSI) e fruto da parceria entre Fórum de Entidades Nacionais da Psicologia Brasileira (FENPB), Biblioteca Dante Moreira Leite do Instituto de Psicologia da Universidade de São Paulo (IP/USP) e do Centro Latino Americano e do Caribe de Informação em Ciência da Saúde - BIREME, que cedeu a metodologia Scientific Eletronic Library Online (SciELO) - modelo de publicação eletrônica de periódicos para países em desenvolvimento. Tem como objetivo contribuir para a visibilidade do conhecimento psicológico e científico gerado nos países da América Latina, a partir da publicação de revistas científicas em acesso aberto (PePSIC, 2016).

A segunda base de dados utilizada foi o SciELO - Scientific Eletronic Library Online. Desenvolvida pela FAPESP (Fundação de Amparo à Pesquisa de São Paulo) é uma base de 
dados virtual que atua em parceria com o BIREME (Centro Latino Americano e do Caribe de Informações em Ciências da Saúde). Abrigam periódicos científico de alta qualidade de acordo com o CNPQ (Conselho Nacional de Desenvolvimento Científico e Tecnológico) e apresenta uma metodologia que se assemelham ao armazenamento de informações científicas, em formato eletrônico. Tem como objetivo o desenvolvimento da metodologia comum para a preparação, armazenamento, disseminação e avaliação da produção científica em formato eletrônico (SciELO, 2016).

A terceira e última base de dados utilizada na pesquisa foi a BVS Brasil, é parte integrante da Biblioteca Virtual em Saúde para América Latina e Caribe, e tem por objetivo convergir as redes temáticas brasileiras da BVS e integrar suas redes de fontes de informação em saúde, fortalecendo-as e dando visibilidade as mesmas por meio do portal da BVS Brasil. As fontes são oriundas das BVS Temáticas Nacionais, obedecendo a seus controles de qualidade e metodologias. E sua criação foi realizada no âmbito da BVS Saúde Pública Brasil, contando com o financiamento do Ministério da Saúde do Brasil (BVS, 2016).

Para esta revisão, realizou-se a seleção dos artigos de maneira aleatória conforme iam aparecendo nas bases de dados eletrônicas, utilizando-se de combinações entre os descritores utilizados nesta pesquisa, realizando-se assim uma leitura flutuante dos materiais coletados.

Após a escolha dos materiais que iriam compor a revisão sistemática, foi realizada uma análise conforme os conteúdos para em seguida atribuir sentido ao material coletado e categorizar por semelhanças de temas tratados tendo em vista o tema maior proposto pela presente pesquisa (BARDIN, 2002). A análise de conteúdo é um método de pesquisa composto por muitas técnicas que propõe estabelecimento de relações para além das existentes nas falas propriamente dita (CAVALCANTE; CALIXTO; PINHEIRO, 2014).

No presente estudo, a análise dos conteúdos foi realizada após a escolha dos artigos pelos títulos e resumos, servindo como maneira de avaliar os artigos secundariamente.

Os critérios de inclusão utilizados nesta pesquisa foram: 1) artigos publicados nos últimos cinco anos, especificamente de 2012-2016; 2) artigos completos e originais; 3) em idioma português; 4) estudos transversais, pesquisas de campo exploratória, estudos de coorte prospectivos e retrospectivo; 5) artigos que apresentavam alguma das palavras chaves no resumo ou título. 
Os critérios de exclusão foram: 1) artigos que não contemplavam o assunto abordado no presente trabalho; 2) que não estavam completos ou disponíveis na íntegra; 3) em outros idiomas; 4) pesquisas com animais; 5) materiais publicados antes de 2012; 6) editoriais e cartas ao editor, séries de casos, de caso-controle e relatos de casos; 7) materiais que deram ênfase a outras areas que não a Psicologia ou equipe multiprofissional.

Foram encontrados 149 artigos, dos quais 17 foram selecionados para constituir a presente pesquisa, enquadrando-se nos critérios de inclusão, conforme o fluxograma abaixo:

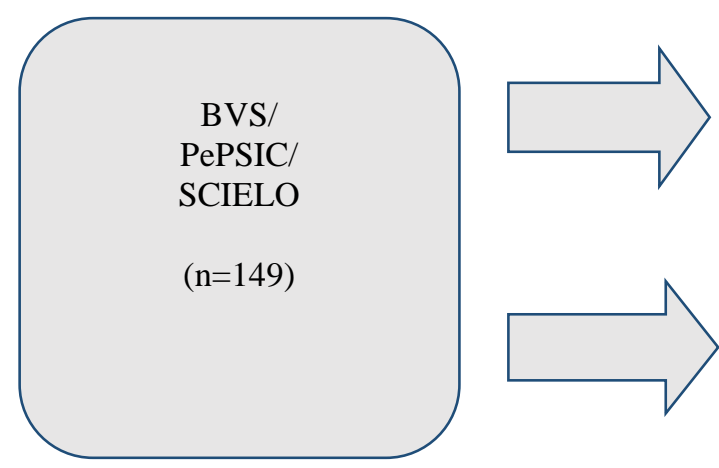

Estudos incluídos nesta revisão $(\mathrm{n}=17)$

- Artigos completos e originais

- Artigos em língua portuguesa. - Artigos publicados entre os anos de 2012 e 2016.

Estudos Excluídos

- Estudos publicados antes de 2012.

- Estudos de revisão de literatura;

- Artigos que tenham dado ênfase a outros assuntos. - Artigos em outros idiomas.

Figura 1 - Fluxograma ilustrativo para realização da seleção dos artigos

Na tabela 1 exposta abaixo, consta a lista dos 17 artigos que foram selecionados para a presente pesquisa a partir da escolha através dos critérios de inclusão e exclusão, sendo dispostos de acordo com o ano de publicação, dos mais recentes aos mais antigos.

$\underline{\text { Tabela } 1 \text { - Artigos selecionados para esse estudo }}$

\begin{tabular}{rl|l}
\hline \multicolumn{1}{l|}{ Artigos } & Categoria \\
\hline 1. & SANCHES; NASCIMENTO; LIMA, 2014 & 1 \\
\hline 2. & SILVA; MELO, 2013 & 1 \\
\hline 3. & SILVA; MELO; PEDROSA, 2013 & 1 \\
\hline 4. & RECH; SILVA; LOPES, 2013 & 1 \\
\hline
\end{tabular}


Id on Line Revista Multidisciplinar e de Psicologia

Id on Line Multidisciplinary and Psycology Journal

\begin{tabular}{c|l}
\hline 5. MELO et al., 2012 & 1 \\
\hline 6. HOSTERT; MOTTA; ENUMO, 2015 & 2 \\
\hline 7. HOSTERT; ENUMO; LOSS, 2014 & 2 \\
\hline 8. LIMA; BARROS; ENUMO, 2014 & 2 \\
\hline 9. GABATTO; ARAÚJO, 2013 & 2 \\
\hline 10. ALVES et al., 2015 & 3 \\
\hline 11. SIQUEIRA et al., 2015 & 3 \\
\hline 12. SILVA et al., 2015 & 3 \\
\hline 13. ALVES; MELO; SOUZA, 2014 & 3 \\
\hline 14. LEVISKI; LANGARO, 2014 & 3 \\
\hline 15. PONTES, PAIS-RIBEIRO, 2014 & 3 \\
\hline 16. PONTES, PAIS-RIBEIRO, 2014 & 3 \\
\hline 17. MAGALHÃES; FRANCO, 2012 & 3 \\
\hline
\end{tabular}

Fonte: Trabalho da autora

\section{Resultados e Discussões}

\section{Análise das informações e categorias escolhidas}

Foram selecionados 17 artigos, dos quais dois foram publicados no ano de 2012, quatro em 2013, sete em 2014 e quatro em 2015. Foi notório que nenhum dos artigos selecionados foi publicado no ano de 2016, sendo possível observar discrepâncias na distribuição ao longo dos anos. Segue as informações no gráfico 1 a seguir.

Gráfico 1 - Distribuição dos artigos selecionados de acordo com o ano de publicação.

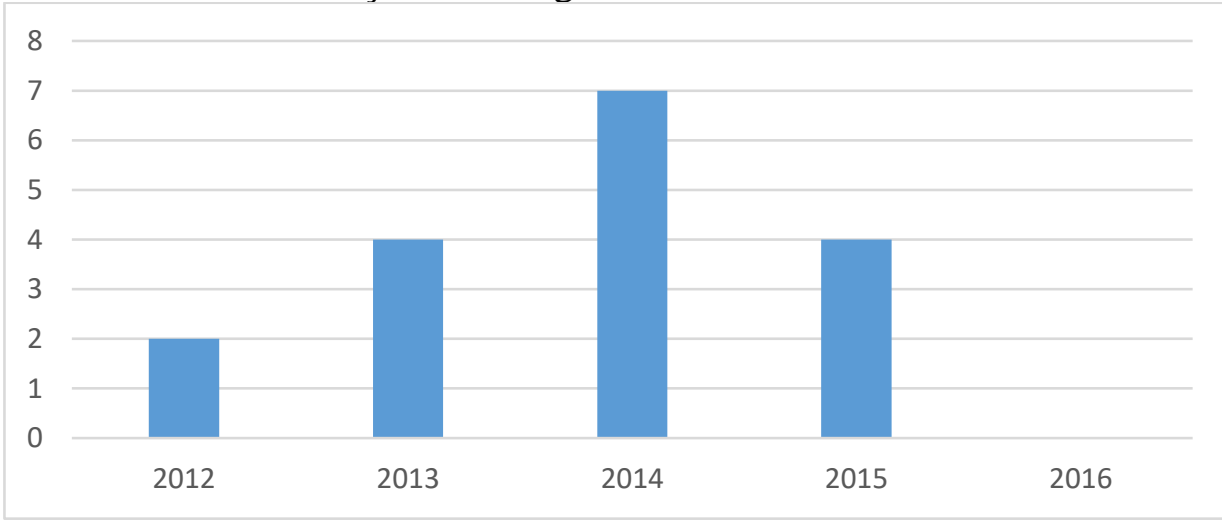


Quadro 1 - Quantidade de autores nos artigos selecionados

\begin{tabular}{|c|c|c|}
\hline Quantidade de autores & Quantidade de artigos & Porcentagem (\%) \\
\hline 2 & 6 & $35,29 \%$ \\
\hline 3 & 7 & $41,18 \%$ \\
\hline 4 & 1 & $5,88 \%$ \\
\hline 5 & 2 & $11,76 \%$ \\
\hline 7 & 1 & $5,88 \%$ \\
\hline Total & 17 & $100 \%$ \\
\hline
\end{tabular}

Fonte: própria pesquisa

Tabela 2 - Artigos que contemplam a categoria 1 - Repercussões do câncer infantil na vivência familiar

\begin{tabular}{|c|c|c|c|c|}
\hline Autor/Tema & Periódico/Ano & $\begin{array}{l}\text { Tipo de } \\
\text { Estudo }\end{array}$ & Amostra & Objetivos e Resultados \\
\hline $\begin{array}{l}\text { SILVA. Patricia } \\
\text { karla de Sousa e; } \\
\text { MELO, Symone } \\
\text { Fernandes de. } \\
\text { Experiência } \\
\text { materna de perda } \\
\text { de um filho com } \\
\text { câncer infantil: } \\
\text { um estudo } \\
\text { fenomenológico. }\end{array}$ & $\begin{array}{l}\text { Revista da } \\
\text { Abordagem } \\
\text { Gestáltica, } \\
2013 \text {. }\end{array}$ & $\begin{array}{l}\text { Estudo } \\
\text { exploratório e } \\
\text { compreensivo } \\
\text { com } \\
\text { delineamento } \\
\text { qualitativo, na } \\
\text { modalidade de } \\
\text { estudo de } \\
\text { caso. }\end{array}$ & 1 mãe. & $\begin{array}{l}\text { Objetivou compreender a } \\
\text { experiência de uma mãe que } \\
\text { vivenciou a perda de um filho em } \\
\text { decorrência de câncer infantil. Com } \\
\text { os resultados foi possível constatar } \\
\text { que a experiência do câncer infantil } \\
\text { é capaz de aproximar cada mãe da } \\
\text { ontológica sensação de desamparo } \\
\text { humano, mobilizando mudanças, e } \\
\text { que a garantia do cuidado, durante } \\
\text { o processo de adoecimento e perda } \\
\text { do filho, favorece uma vivência } \\
\text { autêntica do luto e a abertura de } \\
\text { novas possibilidades em suas vidas. }\end{array}$ \\
\hline $\begin{array}{l}\text { SILVA, Lucelia } \\
\text { Maria Lima da; } \\
\text { MELO, Mônica } \\
\text { Cristina Batista } \\
\text { de; PEDROSA, } \\
\text { Arli Diniz } \\
\text { Oliveira Melo. A } \\
\text { vivência do pai } \\
\text { diante do câncer } \\
\text { infantil. }\end{array}$ & $\begin{array}{l}\text { Psicologia em } \\
\text { Estudo, } 2013 .\end{array}$ & $\begin{array}{l}\text { Pesquisa de } \\
\text { caráter } \\
\text { qualitativo. }\end{array}$ & 11 genitores & $\begin{array}{l}\text { Objetivou compreender a vivência } \\
\text { do pai diante do câncer de um filho } \\
\text { pequeno. Os resultados apontaram } \\
\text { que as mães foram as principais } \\
\text { cuidadoras no tratamento, mas os } \\
\text { pais também desenvolveram } \\
\text { atividades junto a seus filhos } \\
\text { doentes que provocaram várias } \\
\text { mudanças na sua rotina. O } \\
\text { acolhimento e a escuta clínica ou a } \\
\text { criação de grupos de apoio para } \\
\text { este público-alvo são de grande } \\
\text { importância. }\end{array}$ \\
\hline $\begin{array}{l}\text { MELO, Mônica } \\
\text { Cristina Batista } \\
\text { de, et al. O } \\
\text { funcionamento } \\
\text { familiar do } \\
\text { paciente com } \\
\text { câncer. }\end{array}$ & $\begin{array}{l}\text { Psicologia em } \\
\text { Revista, } 2012 .\end{array}$ & $\begin{array}{l}\text { Estudo de } \\
\text { corte } \\
\text { transversal, } \\
\text { com } \\
\text { abordagem } \\
\text { qualitativa. }\end{array}$ & $\begin{array}{l}83 \text { pacientes } \\
\text { oncológicos. }\end{array}$ & $\begin{array}{l}\text { Objetivou compreender como a } \\
\text { família se organiza para lidar com a } \\
\text { doença e o doente. Os resultados } \\
\text { revelam mudanças na organização } \\
\text { familiar após o adoecimento e } \\
\text { tratamento, além de perceber que } \\
\text { os familiares apresentam } \\
\text { flexibilidade para mudar de papéis } \\
\text { para cumprir as tarefas do } \\
\text { cotidiano, cuidar do paciente, e se } \\
\text { organiza tendo como foco fornecer } \\
\text { apoio e proteção a seus membros e }\end{array}$ \\
\hline
\end{tabular}




\begin{tabular}{|c|c|c|c|c|}
\hline & & & & $\begin{array}{l}\text { ao paciente, confirmando a } \\
\text { importância da flexibilidade e do } \\
\text { apoio familiar para a resolução de } \\
\text { problemas e como estratégias em } \\
\text { prol da saúde mental. }\end{array}$ \\
\hline $\begin{array}{l}\text { RECH, Bárbara } \\
\text { Cristina Steffen; } \\
\text { SILVA, Isabela } \\
\text { Machado da; } \\
\text { LOPES, Rita de } \\
\text { Cássia Sobreira. } \\
\text { Repercussões do } \\
\text { câncer infantil } \\
\text { sobre a relação } \\
\text { conjugal. }\end{array}$ & $\begin{array}{l}\text { Psicologia: } \\
\text { Teoria e } \\
\text { Pesquisa, } 2013 .\end{array}$ & $\begin{array}{l}\text { Estudo de caso } \\
\text { coletivo com } \\
\text { abordagem } \\
\text { qualitativa. }\end{array}$ & 4 casais. & $\begin{array}{l}\text { Objetivou investigar as } \\
\text { repercussões do câncer de um filho } \\
\text { sobre o relacionamento conjugal } \\
\text { dos pais, especificamente no que se } \\
\text { refere à coesão, à comunicação e a } \\
\text { à intimidade/sexualidade. Quanto } \\
\text { aos resultados, relatou-se uma } \\
\text { maior coesão relacionada à } \\
\text { sensação de poder contar com o } \\
\text { cônjuge. Quanto à comunicação, } \\
\text { constatou-se o predomínio de temas } \\
\text { relacionados à enfermidade da } \\
\text { criança, mas um silenciamento, } \\
\text { entre os homens, quanto aos } \\
\text { temores vivenciados. A } \\
\text { intimidade/sexualidade mostrou-se } \\
\text { influenciada pela ansiedade } \\
\text { enfrentada. Constatou-se como o } \\
\text { câncer infantil pode exacerbar } \\
\text { características já presentes na } \\
\text { relação, assim como apresentar } \\
\text { novos desafios aos casais. }\end{array}$ \\
\hline $\begin{array}{l}\text { SANCHES, } \\
\text { Mariana } \\
\text { Vendrami Parra; } \\
\text { NASCIMENTO, } \\
\text { Lucila } \\
\text { Castanheira; } \\
\text { LIMA, Regina } \\
\text { Aparecida Garcia } \\
\text { de. Crianças e } \\
\text { adolescentes com } \\
\text { câncer em } \\
\text { cuidados } \\
\text { paliativos: } \\
\text { experiência de } \\
\text { familiares. }\end{array}$ & $\begin{array}{l}\text { Revista } \\
\text { Brasileira de } \\
\text { Enferma-gem, } \\
2014 .\end{array}$ & $\begin{array}{l}\text { Pesquisa } \\
\text { descritiva e } \\
\text { exploratória, } \\
\text { com análise } \\
\text { qualitativa. }\end{array}$ & $\begin{array}{l}14 \text { familiares, } \\
\text { cuidadores de } \\
\text { crianças e } \\
\text { adolescentes } \\
\text { que morreram } \\
\text { com câncer. }\end{array}$ & $\begin{array}{l}\text { Objetivou investigar a experiência } \\
\text { dos familiares no cuidar de crianças } \\
\text { com câncer, em cuidados } \\
\text { paliativos, particularmente nos } \\
\text { cuidados ao final da vida. Como } \\
\text { resultado, percebeu-se que a } \\
\text { experiência da família diante dos } \\
\text { cuidados paliativos foi marcada } \\
\text { pela reorganização familiar } \\
\text { centrada no cuidado da criança e do } \\
\text { adolescente com câncer em } \\
\text { cuidados paliativos. }\end{array}$ \\
\hline
\end{tabular}

Fonte: Própria pesquisa.

Cinco artigos constituíram essa primeira categoria. Ainda é um tema relativamente pouco estudado na literatura, representando $29,41 \%$ dos artigos coletados, mas que vem conquistando o interesse dos pesquisadores em decorrência da importância de saber a respeito de quais as repercussões que o câncer acarreta na vivência familiar, visto que o câncer infantil mobiliza toda a estrutura familiar para o cuidado à criança. 
As repercussões do câncer infantil sobre a vivência familiar, vem sendo debatida na literatura tendo em vista a progressiva necessidade de entender os aspectos envolvidos no diagnóstico do câncer e da necessidade de se trabalhar com a família, visto que o câncer é gerador de grandes mudanças e sofrimento.

Diante dos resultados obtidos nos artigos selecionados, é evidente constatar que há uma reorganização da estrutura familiar e dos papeis desempenados por cada membro da família diante do diagnóstico de câncer e período de cuidados paliativos (FERREIRA et al., 2010; COSTA, 2012; SILVA, MELO, PEDROSA, 2013; SILVA, MELO, 2013; MELO et al., 2012; RECH, SILVA, LOPES, 2013; SANCHES, NASCIMENTO; LIMA, 2014; FARRINHAS, WENDLING, DELLAZZANA-ZASON, 2013; DUPAS et al., 2012; TORQUATO et al., 2012).

Foi prevalente nos estudos de Melo et al. (2012), que a reorganização familiar acontece tendo como ponto central o cuidado à criança doente, a qual é dedicada atenção, cuidado e afeto, corroborando com o estudo realizado por Schneider, Medeiros (2011) que afirma que a hospitalização é um processo que provoca impactos emocionais e o cuidado gira em torno da criança doente no qual os membros da família se reorganizam para garantir o cuidado.

Em pesquisas realizadas por Silva, Melo (2013), Silva, Melo e Pedrosa (2013) e Dupas et al. (2012) foi possível observar que no setor de oncologia pediátrica, as mães são as principais cuidadoras tanto no processo de hospitalização quanto morte da criança. Mais também ressaltase a importância dos pais se fazerem presente no processo de adoecimento e morte o filho. E Visoná, Prevedello, Souza (2012), afirmam a partir dos resultados encontrados na pesquisa, que normalmente são as mulheres que assumem o papel de cuidado, sendo elas as primeiras que intervém no processo de adoecimento de algum membro da família.

O diagnóstico de câncer provoca alterações em toda a estrutura familiar e em seus membros, exigindo flexibilidade para que possam assumir novos papéis com o objetivo de garantir cuidado integral, além de ser comum os familiares abandonarem o autocuidado em prol da dedicação unicamente à criança doente, o que pode ocasionar um distanciamento dos familiares tendo em vista a necessidade de hospitalizações e distanciamento da rotina do lar e das atividades desenvolvidas anterior ao diagnóstico (FERREIRA et al., 2010). Além do fato de ocorrer mudanças emocionais e psicológicas diante do adoecimento de uma criança (AMADOR et al., 2013). 
O câncer é uma doença que demanda um período de tratamento muito grande, além de complicações e sequelas que podem gerar incapacidades funcionais na vida da criança, necessitando pois de cuidado contínuo, o que além de envolver o trabalho de uma equipe multiprofissional, torna-se indispensável a presença da família frente a esse cuidado disponibilizado ao doente. Sendo assim, percebe-se que a família é um apoio do sujeito acometido por neoplasia para enfrentar o processo de adoecimento (VISONÁ; PREVEDELLO; SOUZA, 2012).

\section{Categoria 2 - Tipos de Coping utilizados na hospitalização}

Por coping entende-se as estratégias pessoais utilizadas para lidar com situações de grandes dificuldades e tem como objetivo diminuir o sofrimento provocado pela situação estressante e colaborar positivamente para a adaptação dos sujeitos a nova realidade (FETSCH et al., 2016).

Tabela 3 - Artigos que contemplam a categoria 2 - Tipos de Coping utilizados na hospitalização.

\begin{tabular}{|c|c|c|c|c|}
\hline Autor/Tema & Periódico/Ano & $\begin{array}{l}\text { Tipo de } \\
\text { Estudo }\end{array}$ & Amostra & Objetivos e Resultados \\
\hline $\begin{array}{l}\text { HOSTERT, Paula } \\
\text { Coimbra da Costa } \\
\text { Pereira; MOTTA, } \\
\text { Alessandra } \\
\text { Brunoro; ENUMO, } \\
\text { Sônia Regina } \\
\text { Fiorim. Coping da } \\
\text { hospitalização em } \\
\text { crianças com } \\
\text { câncer: a } \\
\text { importância da } \\
\text { classe hospitalar. }\end{array}$ & $\begin{array}{l}\text { Estudos de } \\
\text { Psicologia / } \\
\text { Campinas, } \\
2015 .\end{array}$ & $\begin{array}{l}\text { Pesquisa } \\
\text { descritiva } \\
\text { com } \\
\text { abordagem } \\
\text { qualitativa }\end{array}$ & $\begin{array}{l}18 \text { crianças } \\
\text { com câncer } \\
\text { com idades } \\
\text { entre } 6 \text { e } 12 \\
\text { anos. }\end{array}$ & $\begin{array}{l}\text { Objetivou descrever as estratégias de } \\
\text { enfrentamento de crianças com câncer } \\
\text { para lidar com a hospitalização, } \\
\text { analisando a importância da Classe } \\
\text { Hospitalar. Os comportamentos mais } \\
\text { referidos foram: brincar, conversar, } \\
\text { assistir TV, tomar remédio, estudar, } \\
\text { sentir raiva e fazer chantagem; e as } \\
\text { famílias de Coping mais identificadas } \\
\text { foram ruminação e distração. E o } \\
\text { padrão de Coping revelou } \\
\text { comportamentos e estratégias } \\
\text { favoráveis ao enfrentamento da } \\
\text { hospitalização durante o período na } \\
\text { Classe Hospitalar, indicando } \\
\text { possíveis benefícios desta para a } \\
\text { criança em tratamento contra o } \\
\text { câncer. }\end{array}$ \\
\hline $\begin{array}{l}\text { HOSTERT, Paula } \\
\text { Coimbra da Costa } \\
\text { Pereira; ENUMO, } \\
\text { Sônia Regina } \\
\text { Fiorim; LOSS, } \\
\text { Alessandra Brunoro } \\
\text { Motta. Brincar e }\end{array}$ & $\begin{array}{l}\text { Revista } \\
\text { Psicologia: } \\
\text { Teoria e } \\
\text { Prática, } 2014 .\end{array}$ & $\begin{array}{l}\text { Estudo } \\
\text { descritivo de } \\
\text { abordagem } \\
\text { qualitativa. }\end{array}$ & $\begin{array}{l}18 \text { crianças } \\
\text { com idades } \\
\text { entre } 6 \text { e } 12 \\
\text { anos. }\end{array}$ & $\begin{array}{l}\text { Objetivou descrever as preferencias } \\
\text { lúdicas de crianças com câncer, na } \\
\text { classe hospitalar. Nos resultados foi } \\
\text { possível observar que as brincadeiras } \\
\text { preferidas foram: desenhar, assistir à } \\
\text { TV e ler gibi. As crianças } \\
\text { apresentaram problemas }\end{array}$ \\
\hline
\end{tabular}




\begin{tabular}{|c|c|c|c|c|}
\hline $\begin{array}{l}\text { problemas de } \\
\text { comportamento de } \\
\text { crianças com câncer } \\
\text { de classes } \\
\text { hospitalares. }\end{array}$ & & & & $\begin{array}{l}\text { comportamentais, como dor de cabeça } \\
\text { e medo. Além de alta frequência de } \\
\text { problemas que indica a importância } \\
\text { da assistência psicológica, que pode } \\
\text { ser realizada por meio da associação } \\
\text { de recursos lúdicos às técnicas } \\
\text { psicológicas adequadas às demandas } \\
\text { dos contexto da doença e da } \\
\text { hospitalização. E o brincar aparece } \\
\text { durante o período na classe hospitalar, } \\
\text { indicando possíveis benefícios dessa } \\
\text { para a brincadeira no hospital e no } \\
\text { tratamento dessas crianças. }\end{array}$ \\
\hline $\begin{array}{l}\text { LIMA, Ana Sofia; } \\
\text { BARROS, Luísa; } \\
\text { ENUMO, Sônia } \\
\text { Regina Fiorim. } \\
\text { Enfrentamento em } \\
\text { crianças } \\
\text { portuguesas } \\
\text { hospitalizadas por } \\
\text { câncer: comparação } \\
\text { de dois } \\
\text { instrumentos de } \\
\text { avaliação. }\end{array}$ & $\begin{array}{l}\text { Estudos de } \\
\text { Psicologia/ } \\
\text { Campinas, } \\
2014 .\end{array}$ & $\begin{array}{l}\text { Estudo } \\
\text { exploratório. }\end{array}$ & $\begin{array}{l}19 \text { Crianças } \\
\text { com câncer } \\
\text { com idades } \\
\text { entre } 6 \text { e } 12 \\
\text { anos e } \\
\text { cuidadores. }\end{array}$ & $\begin{array}{l}\text { Objetivou comparar duas } \\
\text { metodologias de avaliação do } \\
\text { enfrentamento em contexto de } \\
\text { hospitalização pediátrica. Os } \\
\text { resultados apontaram níveis reduzidos } \\
\text { de perturbação comportamental e } \\
\text { sofrimento, tanto na avaliação de } \\
\text { crianças quanto na dos pais. A } \\
\text { amostra apresentou diversidade de } \\
\text { estratégias de enfrentamento, bem } \\
\text { como preponderância de } \\
\text { comportamentos facilitadores em } \\
\text { ambas as escalas, com predominância } \\
\text { de suporte social e distração, além de } \\
\text { pensamentos mágicos e ruminação. } \\
\text { Ambas as escalas tiveram repostas } \\
\text { semelhantes para suporte social e } \\
\text { distração, mas não para outras } \\
\text { estratégias. }\end{array}$ \\
\hline $\begin{array}{l}\text { GABATTO, } \\
\text { Caroline Amado; } \\
\text { ARAUJO, Tereza } \\
\text { Cristina Cavalcanti } \\
\text { Ferreira de. } \\
\text { Religiosidade e } \\
\text { espiritualidade em } \\
\text { oncologia: } \\
\text { concepções de } \\
\text { profissionais da } \\
\text { saúde. }\end{array}$ & $\begin{array}{l}\text { Psicologia, } \\
\text { USP, } 2013 .\end{array}$ & $\begin{array}{l}\text { Estudo } \\
\text { descritivo e } \\
\text { exploratório } \\
\text { de } \\
\text { abordagem } \\
\text { quantiquali- } \\
\text { tativa, } \\
\text { organizado } \\
\text { em duas } \\
\text { etapas. }\end{array}$ & $\begin{array}{l}85 \\
\text { profissionais } \\
\text { de saúde. }\end{array}$ & $\begin{array}{l}\text { Objetivou conhecer, analisar e } \\
\text { compreender as concepções de } \\
\text { profissionais de saúde acerca da } \\
\text { associação entre religiosidade, } \\
\text { espiritualidade e saúde em oncologia. } \\
\text { Os resultados indicaram que temas } \\
\text { religiosos/espirituais são frequentes } \\
\text { nos atendimentos, os integrantes dos } \\
\text { grupos relatam não ter recebido } \\
\text { nenhuma formação acadêmica para } \\
\text { abordar a temática e os participantes } \\
\text { evidenciam concepções positivas } \\
\text { sobre a influência da } \\
\text { religiosidade/espiritualidade para a } \\
\text { saúde, com efeitos negativos em } \\
\text { menor proporção. }\end{array}$ \\
\hline
\end{tabular}

Fonte: Própria pesquisa.

Quatro artigos constituíram essa segunda categoria, sendo abordado os artigos referentes às formas de coping utilizadas diante do processo de hospitalização. 
Questões relativas à religiosidade e espiritualidade foram estudadas como uma forma de enfretamento do câncer. Na pesquisa desenvolvida por Gabatto, Araújo (2013), foi possível observar que as influências da religiosidade/espiritualidade foram descritas majoritariamente de forma positivas tanto na perspectiva de pacientes quanto de familiares. Mas também foram percebidas influências negativas. Corroborando com essa ideia, Silva et al. (2008), afirmam que a fé/espiritualidade é uma ferramenta significativa dos pacientes e familiares para enfrentar o diagnóstico e tratamento da doença oncológica, além de ser importante para entendimento da situação que está sendo vivenciada.

O tema espiritualidade/religiosidade foi alvo de pesquisa para outros autores. Guerrero et al. (2011), compreendeu a relação existente entre espiritualidade e as doenças oncológicas como sendo, o câncer uma doença que amedronta e a espiritualidade como fonte de renovação. Souza et al. (2015), desenvolveram uma pesquisa com adolescentes com câncer e nos resultados foi possível observar que todos os participantes afirmaram que as crenças religiosas e espirituais foram influentes para a recuperação da saúde. E, pesquisas realizadas por Fornazari, Ferreira (2010), demostram aspectos relacionados ao enfrentamento religioso/espiritual presente nos relatos de todas as participantes (sendo presente desde o suporte emocional até o controle dos sintomas).

Na concepção Rezende, Schall, Modena (2011), a espiritualidade/religiosidade é importante para os familiares servindo como fonte de alívio tendo em vista o sofrimento que é ocasionado pela doença de um filho e de todas as dificuldades que são encontrados durante o processo cuidado da criança. E na concepção de Fagundes et al. (2015), a religião é um aspecto que marca a vida do ser humano, e exerce influência significativa nas ações dos sujeitos em todos os momentos.

Dos quatro artigos que compões essa categoria, três evidenciaram a grande importância de comportamentos de distração - assistir TV, brincar, estudar, ler gibi, conversar, ouvir música, dançar, rezar entre outros, além das ruminações como formas das crianças de enfrentarem o processo de hospitalização. Esse dado corrobora com a pesquisa realizada por Morais, Enumo (2008), na qual foi notório que os comportamentos de ruminação se constituíram na primeira forma de enfrentamento mais utilizada pelas crianças e os comportamentos de distração foi apresentada como a segunda forma de enfrentamento mais utilizada. 
Dois dos artigos citados, elencam a importância da classe hospitalar no processo de hospitalização (HOSTERT, MOTTA, ENUMO, 2015; HOSTERT, ENUMO, LOSS, 2014). Por classe hospitalar entende-se as estratégias utilizadas para garantir à criança que está hospitalizada o direito de continuar no processo de aprendizagem, garantindo a experiência de aprender, e de desenvolver-se cognitivamente e facilitar o processo de relacionamento com outras crianças (ZOMBINI et al, 2012).

E em estudo realizado por Azevêdo (2011), é perceptível os benefícios da brincadeira/brincar para crianças hospitalizadas com câncer. O que vai de encontro a ideia de Hostert, Motta, Enumo (2015) e Hostert, Enumo, Loss (2014).

\section{Categoria 3 - Cuidados Paliativos: experiência de pacientes, familiares e profissionais da equipe multiprofissional}

Tabela 4 - Artigos que contemplam a categoria 3 - Cuidados Paliativos: experiência de pacientes, familiares e profissionais da equipe multiprofissional.

\begin{tabular}{|c|c|c|c|c|}
\hline Autor/Tema & Periódico/Ano & $\begin{array}{l}\text { Tipo de } \\
\text { Estudo }\end{array}$ & Amostra & Objetivos e Resultados \\
\hline $\begin{array}{l}\text { ALVES, Railda } \\
\text { Fernandes et al. } \\
\text { Cuidados paliativos: } \\
\text { desafios para } \\
\text { cuidadores e } \\
\text { profissionais de } \\
\text { saúde. }\end{array}$ & $\begin{array}{l}\text { Fractal: Revista } \\
\text { de Psicologia, } \\
2015 .\end{array}$ & $\begin{array}{l}\text { Pesquisa com } \\
\text { abordagem } \\
\text { quantiquali- } \\
\text { tativa. }\end{array}$ & $\begin{array}{l}59 \\
\text { profissionais } \\
\text { de saúde e } \\
\text { cuidadores } \\
\text { não } \\
\text { profissionais. }\end{array}$ & $\begin{array}{l}\text { Objetivou conhecer os discursos } \\
\text { e as práticas sobre os CP, e as } \\
\text { dificuldades no exercício desses } \\
\text { cuidados. A análise dos } \\
\text { discursos mostrou que os CP são } \\
\text { entendidos como práticas } \\
\text { voltadas ao alívio da dor; ao } \\
\text { amparo à família do paciente e } \\
\text { ao uso de medicamento, além de } \\
\text { apontar que existem dúvidas } \\
\text { para os fazeres do psicólogo nos } \\
\mathrm{CP} \text {, ainda que sejam efetuadas } \\
\text { práticas correlatas. }\end{array}$ \\
\hline $\begin{array}{l}\text { SIQUEIRA, Hilze } \\
\text { Benigno de Oliveira } \\
\text { Moura et al. } \\
\text { Expressão da dor na } \\
\text { criança com câncer: } \\
\text { uma compreensão } \\
\text { fenomenológica. }\end{array}$ & $\begin{array}{l}\text { Estudos de } \\
\text { Psicologia, } \\
2015 .\end{array}$ & $\begin{array}{l}\text { Estudo } \\
\text { exploratório } \\
\text { descritivo com } \\
\text { abordagem } \\
\text { qualitativa. }\end{array}$ & $\begin{array}{l}17 \text { crianças } \\
\text { com criança. }\end{array}$ & $\begin{array}{l}\text { Objetivou compreender como } \\
\text { crianças com câncer expressam } \\
\text { a experiência dolorosa no } \\
\text { decorrer do processo da doença. } \\
\text { Quanto aos resultados, as } \\
\text { crianças foram capazes de } \\
\text { entender a dor } \\
\text { multidimensionalmente, } \\
\text { comunicando-a de modo } \\
\text { satisfatório. Tal compreensão } \\
\text { pode ser influenciada pela } \\
\text { intersubjetividade, história de } \\
\text { vida, aspectos psicossociais e, } \\
\text { pelo entendimento adquirido } \\
\text { durante o adoecimento. }\end{array}$ \\
\hline
\end{tabular}




\begin{tabular}{|c|c|c|c|c|}
\hline $\begin{array}{l}\text { SILVA, Adriana } \\
\text { Ferreira da et al. } \\
\text { Cuidados paliativos } \\
\text { em oncologia } \\
\text { pediátrica: } \\
\text { percepções, saberes e } \\
\text { práticas na } \\
\text { perspectiva da } \\
\text { equipe } \\
\text { multiprofissional. }\end{array}$ & $\begin{array}{l}\text { Rev. Gaúcha } \\
\text { Enferm., } 2015 .\end{array}$ & $\begin{array}{l}\text { Pesquisa } \\
\text { qualitativa, } \\
\text { exploratória e } \\
\text { descritiva. }\end{array}$ & $\begin{array}{l}9 \\
\text { profissionais } \\
\text { integrantes da } \\
\text { equipe } \\
\text { multidiscipli- } \\
\text { nar. }\end{array}$ & $\begin{array}{l}\text { Objetivou conhecer as } \\
\text { percepções, saberes e práticas da } \\
\text { equipe multiprofissional na } \\
\text { atenção às crianças em cuidados } \\
\text { paliativos em unidade de } \\
\text { oncologia pediátrica. Quanto } \\
\text { aos resultados, percebeu-se que } \\
\text { a equipe sofre, igualmente, com } \\
\text { a morte da criança e, de forma } \\
\text { semelhante à família, move-se } \\
\text { em direção à construção de } \\
\text { mecanismos de enfrentamento } \\
\text { para a elaboração do luto. }\end{array}$ \\
\hline $\begin{array}{l}\text { ALVES, Railda } \\
\text { Fernandes; MELO, } \\
\text { Myriam; SOUSA, } \\
\text { Valéria. Saberes e } \\
\text { práticas sobre } \\
\text { cuidados paliativos } \\
\text { segundo psicólogos } \\
\text { atuantes em hospitais } \\
\text { públicos. }\end{array}$ & $\begin{array}{l}\text { Psicologia, } \\
\text { Saúde \& } \\
\text { Doença, } 2014 .\end{array}$ & $\begin{array}{l}\text { Pesquisa de } \\
\text { abordagem } \\
\text { quantiquqli- } \\
\text { tativa. }\end{array}$ & 21 psicólogos. & $\begin{array}{l}\text { Objetivou conhecer os saberes e } \\
\text { as práticas sobre os CP dos } \\
\text { psicólogos atuantes em dois } \\
\text { hospitais públicos da cidade de } \\
\text { Campina Grande-PB-Brasil. Os } \\
\text { resultados apontam uma amostra } \\
\text { essencialmente feminina } \\
\text { (90,5\%) e 95\% confirmaram ter } \\
\text { contato com pacientes terminais. } \\
\text { A pesquisa apontou que as } \\
\text { práticas estão voltadas para } \\
\text { técnicas psicológicas, } \\
\text { assistências ao paciente, à } \\
\text { família e à equipe de saúde. } \\
\text { Existem dificuldades no } \\
\text { relacionamento com essa equipe } \\
\text { e a formação acadêmica é } \\
\text { deficitária. A importância da } \\
\text { humanização é reconhecida, } \\
\text { ainda que não seja praticada } \\
\text { como deveria. Há uma } \\
\text { necessidade de sistematização } \\
\text { em CP como guias das ações. }\end{array}$ \\
\hline $\begin{array}{l}\text { LEVISKI, Bárbara } \\
\text { Luckow; } \\
\text { LANGARO, } \\
\text { Fabíola. O olhar } \\
\text { humano sobre a vida: } \\
\text { a consciência da } \\
\text { finitude. }\end{array}$ & $\begin{array}{l}\text { Rev. SBPH, } \\
2014 .\end{array}$ & $\begin{array}{l}\text { Pesquisa } \\
\text { exploratória de } \\
\text { caráter } \\
\text { qualitativo. }\end{array}$ & $\begin{array}{l}9 \text { pacientes } \\
\text { em cuidados } \\
\text { paliativos. }\end{array}$ & $\begin{array}{l}\text { Objetivou compreender a } \\
\text { experiência de pacientes e/ou } \\
\text { familiares/cuidadores no } \\
\text { adoecimento e morte. A análise } \\
\text { resultou em três categorias: } \\
\text { tomada de decisão, } \\
\text { comunicação e sentimentos na } \\
\text { experiência de adoecer. Os } \\
\text { cuidados paliativos mostraram } \\
\text { contribuir na qualidade de vida e } \\
\text { de morte. O acolhimento aos } \\
\text { paciente e familiares é ainda } \\
\text { fragmentado, envolvendo } \\
\text { dificuldades como falta de } \\
\text { preparo das equipes } \\
\text { assistenciais, negação da família } \\
\text { em relação ao quadro clínico, } \\
\text { contato escasso entre paciente e }\end{array}$ \\
\hline
\end{tabular}




\begin{tabular}{|c|c|c|c|c|}
\hline & & & & $\begin{array}{l}\text { família e a influência da cultura } \\
\text { sobre o conceito de morte. }\end{array}$ \\
\hline $\begin{array}{l}\text { PONTE, Ana } \\
\text { Carolina Silva L. C.; } \\
\text { PAIS-RIBEIRO, } \\
\text { José Luís. O bem- } \\
\text { estar do doente } \\
\text { seguido em cuidados } \\
\text { paliativos (CP): } \\
\text { comparação entre a } \\
\text { perspectiva do } \\
\text { doente e da família. }\end{array}$ & $\begin{array}{l}\text { Psicologia, } \\
\text { Saúde \& } \\
\text { Doença, } 2014 .\end{array}$ & $\begin{array}{l}\text { Estudo } \\
\text { transversal e } \\
\text { exploratório, } \\
\text { de comparação } \\
\text { de grupo. }\end{array}$ & $\begin{array}{l}74 \text { doentes e } \\
83 \text { familiares. }\end{array}$ & $\begin{array}{l}\text { Objetivou comparar a } \\
\text { perspectiva do doente e da } \\
\text { família acerca do bem-estar do } \\
\text { doente paliativo: nível e fatores } \\
\text { preponderantes para maximizar. } \\
\text { Quanto aos resultados, doente e } \\
\text { família observam o nível de } \\
\text { bem-estar como razoável e } \\
\text { avaliam de forma semelhante a } \\
\text { maioria dos fatores importantes } \\
\text { para maximizar. Encontrou-se } \\
\text { diferenças significativas } \\
\text { estatisticamente no grau de } \\
\text { importância atribuído aos } \\
\text { fatores de estar consciente, ver } \\
\text { opções de tratamento seguidas } \\
\text { de sentir que a vida teve sentido. }\end{array}$ \\
\hline $\begin{array}{l}\text { PONTE, Ana } \\
\text { Carolina Silva L. C.; } \\
\text { PAIS-RIBEIRO, } \\
\text { José Luís. O bem- } \\
\text { estar em cuidados } \\
\text { paliativos: } \\
\text { perspectiva do } \\
\text { doente versus } \\
\text { profissionais de } \\
\text { saúde. }\end{array}$ & $\begin{array}{l}\text { Psicologia, } \\
\text { Saúde \& } \\
\text { Doença, } 2014 .\end{array}$ & $\begin{array}{l}\text { Estudo } \\
\text { transversal e } \\
\text { exploratório, } \\
\text { de comparação } \\
\text { de grupo }\end{array}$ & $\begin{array}{l}74 \text { doentes e } \\
78 \\
\text { profissionais } \\
\text { de saúde. }\end{array}$ & $\begin{array}{l}\text { Objetivou comparar a } \\
\text { perspectiva do doente e dos } \\
\text { profissionais de saúde acerca do } \\
\text { bem-estar do paciente paliativo. } \\
\text { Como resultado, é possível } \\
\text { revelar que, com exceção da } \\
\text { importância da ausência da dor, } \\
\text { há existência de diferenças } \\
\text { estatisticamente significativas } \\
\text { entre os grupos em todas as } \\
\text { dimensões avaliadas. O bem- } \\
\text { estar do doente paliativo é } \\
\text { apontado como razoável pelos } \\
\text { próprios doentes e elevado pelos } \\
\text { profissionais de saúde. Há } \\
\text { distanciamento de opiniões } \\
\text { também quanto ao nível de } \\
\text { importância atribuída pelos } \\
\text { profissionais de saúde a } \\
\text { aspectos considerados } \\
\text { prioritários pelos doentes. }\end{array}$ \\
\hline $\begin{array}{l}\text { MAGALHÃES, } \\
\text { Suzane Bandeira; } \\
\text { FRANCO, Anamelia } \\
\text { Lins e Silva. } \\
\text { Experiência de } \\
\text { profissionais e } \\
\text { familiares de } \\
\text { pacientes em } \\
\text { cuidados paliativos. }\end{array}$ & $\begin{array}{l}\text { Arquivos } \\
\text { Brasileiros de } \\
\text { Psicologia, } \\
2012 \text {. }\end{array}$ & $\begin{array}{l}\text { Investigação } \\
\text { qualitativa } \\
\text { com } \\
\text { abordagem } \\
\text { hermenêutica. }\end{array}$ & $\begin{array}{l}10 \text { cuidadores } \\
\text { e um grupo } \\
\text { focal. }\end{array}$ & $\begin{array}{l}\text { Objetivou compreender a } \\
\text { experiência de cuidadores e } \\
\text { profissionais frente à morte de } \\
\text { pacientes com câncer em regime } \\
\text { de cuidados paliativos em fase } \\
\text { terminal. Quanto aos resultados, } \\
\text { as análises possibilitaram } \\
\text { afirmar que os cuidadores, tanto } \\
\text { profissionais quanto familiares, } \\
\text { reconhecem a experiência como } \\
\text { um processo que os constitui ao } \\
\text { longo do tempo, e os desafios do } \\
\text { cuidado em torno da morte são } \\
\text { objetos pertinentes de reflexão. }\end{array}$ \\
\hline
\end{tabular}

Fonte: Própria pesquisa. 
Oito artigos constituíram essa terceira categoria e foi debatido os cuidados paliativos de acordo com a experiência do paciente, dos familiares e da equipe multiprofissional.

Diante da análise dos artigos foi perceptível que há preocupação dos profissionais em ofertar um cuidado humanizado porém ainda se encontram inúmeras dificuldades para efetivá-lo. Assim como foi possível observar que existem dificuldades no relacionamento entre os profissionais de saúde (ALVES, MELO, SOUSA, 2014; ALVES et al., 2015; LEVISKI, LANGARO, 2014).

Quanto ao significado atribuído aos cuidados paliativos, foi percebido principalmente como alívio da dor, acolhimento à família da criança doente e a utilização de medicamentos para o alívio da dor e do sofrimento (ALVES et al., 2015; CARDOSO et al., 2013). E complementando a ideia, Leviski, Langaro (2014), afirmam que os cuidados paliativos são importantes para promoção de qualidade de vida e de morte.

Em estudo realizado por Silva et al. (2015), o trabalho dos profissionais nos cuidados paliativos é diferente ao passo que tira o foco da cura, tendo como objetivo promover qualidade de vida e humanização do cuidar.

Pesquisa realizada por Cardoso et al. (2013), mostrou que os profissionais abarcaram a experiência em cuidados paliativos nos seguintes aspectos: controle dos sintomas e humanização no processo de assistência, vivência do processo de terminalidade e ressignificação do cuidado, bem como um desafios para a equipe multiprofissional que trabalha em cuidados paliativos.

Siqueira et al. (2015) afirmam que a criança doente é capaz de compreender a dor e comunicá-la de forma clara e objetiva. E que a compreensão que a criança apresenta diante de sua doença é fortemente influenciada pelas experiências anteriores, aspectos psicossociais, e pelo entendimento que a criança obtém diante do processo de adoecimento. Quanto à percepção que a família tem do adoecimento do filho, Sanches, Nascimento, Lima (2014), afirmam que esta percebe as mudanças que ocorrem quando a doença está se agravando e que a presença da família no processo de cuidados paliativos é permeada, ao mesmo tempo, por um forte sentimento de esperança e sentimentos de solidão e sofrimento.

Silveira, Ciampone, Gutierrez (2014), afirmam que no trabalho em cuidados paliativos o desgaste dos profissionais está diretamente relacionada ao sentimento de impotência, tendo 
em vista que nem sempre o profissional pode proporcionar ao paciente e familiares a assistência necessária.

Quanto à preparação acadêmica para lidar com pacientes em cuidados paliativos, percebe-se ainda uma precarização (ALVES, MELO, SOUSA, 2014). Esse dado corrobora com a pesquisa realizada Hermes, Lamarca (2013), quando afirmam que é necessário uma reformulação das grades curriculares para que os profissionais possam ser estimulados a debaterem a temática de cuidados paliativos e assim adquirir propriedades para trabalhar com os pacientes que estão fora das possibilidades curativas e com situações de morte.

Em estudos realizados por Ponte, Pais-Ribeiro ${ }^{1}$ (2014) e Ponte, Pais-Ribeiro² (2014), foi perceptível que há diferenças significativas entre a percepção de familiares, paciente e profissionais de saúde acerca do trabalho que é disponibilizado em cuidados paliativos. Enquanto os profissionais avaliam o bem estar como elevado, o familiar e o doente avaliam como moderado.

Silva et al. (2015), afirmam que a equipe multiprofissional também sofre com o morte da criança e assim como a família, busca encontrar mecanismos para enfrentar o perda e elaborar o luto.

Quanto ao papel do psicólogo na equipe multiprofissional de cuidados paliativos, ainda é um trabalho que envolve muitas dúvidas, sendo necessário uma maior sistematização para a atuação dos profissionais (ALVES et al., 2015).

Os cuidadores profissionais e não profissionais reconhecem a necessidade do psicólogo na equipe de cuidados paliativos, já que este profissional está apto para disponibilizar aos familiares, paciente e equipe uma escuta especializada, ajudando-os a elaborar os sentimentos decorrentes do agravamento da doença (ALVES et al., 2015).

\section{Conclusões}

Diante dos estudos, observa-se que a produção científica na temática da equipe multiprofissional de cuidados paliativos em oncologia pediátrica é bastante incipiente. Sendo possível enxergar algumas lacunas ainda não estudadas na literatura, necessitando pois de uma 
maior atenção dos pesquisadores, em especial os psicólogos, tendo em vista a necessidade de mais pesquisas na área dos cuidados paliativos infantil.

Os resultados permitiram identificar a necessidade de estimular os profissionais a pesquisarem a respeito dessa temática, tornando-se necessário aos profissionais serem mais ativos na produção de conhecimento e de bases científicas para uma atuação mais efetiva diante dos paciente e familiares que necessitam de cuidado diante da progressão da doença e aproximação da morte.

Outro aspecto que ficou evidente diante dos resultados é o fato de que a preparação acadêmica é insuficiente para atuação nos cuidados paliativos sendo necessário aos profissionais uma qualificação específica para manejar esse cuidado e lidar com as demandas presentes nesse tipo de serviço. E que a humanização é fator de suma importância para a atuação em cuidados paliativos, porém ainda encontram-se inúmeras dificuldades para executá-la.

Identificou-se que a morte é um fator bastante presente no setor da oncologia pediátrica. E que o diagnóstico de câncer infantil provoca grandes e abruptas mudanças na rotina familiar, necessitando de uma reorganização familiar e mudança dos papéis assumidos por cada membro da casa. Tendo em vista esse dado, faz-se necessária a atuação do psicólogo para auxiliar o paciente e seus familiares no entendimento da nova situação que estão vivenciando, assim como da equipe multiprofissional para dar assistência integral ao sujeito.

Observou-se também que familiares e pacientes se utilizam de estratégias diversas para lidar com a situação causadora de estresse e sofrimento. Entre as estratégias utilizadas estão a religiosidade/espiritualidade, comportamentos de distração e de ruminação e a classe hospitalar. Este trabalho não pretende esgotar os estudos acerca desse tema, mas produzir novas inquietações com o propósito de estimular os profissionais a pensarem mais a respeito da importância da humanização nessa nova forma de cuidar empregada pelos cuidados paliativos. É uma tentativa de promover maiores debates e produções científicas acerca da importância da equipe de cuidados paliativos, dando uma ênfase especial ao profissional de psicologia, por ser a área de formação das autoras. Buscando pois, contribuir com uma formação qualificada e consciente dos pacientes aos quais as terapêuticas curativas já não eficazes e para o surgimento de novas reflexões acerca da temática, em especial para os psicólogos. 


\section{Referências}

ALCÂNTARA, Tainara Vasconcelos de et al. Intervenções psicológicas na sala de espera: estratégias no contexto da oncologia pediátrica. Rev. SBPH, v.16, n² 2, Rio de Janeiro, 2013. Disponível em: <http://pepsic.bvsalud.org/pdf/rsbph/v16n2/v16-n2a08.pdf>

ALMEIDA, Edilene Joceli de et al. Dor e perda: análise do processo do luto. Revista de Psicologia da IMED, v.7, n.1, 2015. Disponível em: <https://webcache.googleusercontent.com/search?q=cache:r4BEyPEAslgJ:https://dialnet.unirioja.es/descarga/articulo/51 55064.pdf $+\& \mathrm{~cd}=1 \& \mathrm{hl}=\mathrm{pt}-\mathrm{BR} \& \mathrm{ct}=\mathrm{clnk} \& \mathrm{gl}=\mathrm{br}>$

ALVES, Railda Fernandes et al. Cuidados paliativos: desafios para cuidadores e profissionais de saúde. Fractal: Revista de Psicologia, v.27, n.2, 2015. Disponível em: <http://www.scielo.br/pdf/fractal/v27n2/1984-0292-fractal-27-2-0165.pdf>

ALVES, Railda Fernandes et al. Saberes e práticas sobre cuidados paliativos segundo psicólogos atuantes em hospitais públicos. Psicologia, Saúde \& Prática, v.15, n.1, 2014. Disponível em: <http://www.redalyc.org/articulo.oa?id=36231157-008>

AMADOR, Daniela Doulavince et al. Repercussões do câncer infantil para o cuidador familiar: uma revisão integrativa. Revista Brasileira de Enfermagem, v.66, n.2, Brasília, 2013. Disponível em: 〈http://www.scielo.br/pdf/reben/v66n2/17.pdf>

AMADOR, Daniela Doulavince et al. A vivência do cuidado em oncologia pediátrica e a busca pela produção do conhecimento. Revista Enfermagem UFPE online, v.4, n.2, 2010. Disponível em: <https://www.google.com.br/url?sa=t\&rct=j\&q=\&esrc=s\&source $=$ web $\& c d=2 \& c a d=r j a \& u a c t=8 \& v e d=0 a h U K E w j 8 y e G p w I b Q A h U C D Z A K H X g 4 A a$ AQFggpMAE\&url=http $\% 3 \mathrm{~A} \% 2 \mathrm{~F} \% 2 \mathrm{Fwww}$.revista.ufpe.br\%2Frevistaenfermagem $\% 2$ Findex. php $\% 2$ Frevista $\% 2$ Farticle $\% 2 F d o w n l o a d \% 2 F 851 \% 2 F 1315 \&$ usg=AFQjCNFahmqbkCmhEWu aEQvLsU9M59sEPA>

ANGERAMI-CAMON, Valdemar Augusto. O psicólogo no hospital. In Psicologia hospitalar: teoria e prática. $2^{\mathrm{a}}$ ed. revista e ampliada. São Paulo: Cengage Learning, 2012. p. 01-14.

ARRUDA-COLLI, Mariana Noronha Ferraz de, et al. Intervenção psicológica com familiares enlutados em oncologia pediátrica: revisão de literatura. Revista de Psicologia: Teoria e Prática. V.17, n.1, p.20-35. São Paulo, 2015. Disponível em: <http://pepsic.bvsalud.org/pdf/ptp/v17n2/02.pdf>

AZÊVEDO, Adriano Valério dos Santos. O brincar da criança com câncer no hospital: análise da produção científica. Estudos de Psicologia, v.28, n.4, Campinas, 2011. Disponível em: <http://www.scielo.br/pdf/estpsi/v28n4/15.pdf>

BARDIN, Laurence. Análise de conteúdo. Lisboa: Edições 70, 2002. 
BERNARDO, Patrícia Pinna. Arteterapia e cuidados paliativos: mitologia e qualidade de vida. In: SANTOS, Franklin Santana. Cuidados paliativos: diretrizes, humanização e alívio dos sintomas. $1^{a}$ ed. São Paulo: Editora Atheneu, 2011. p. 240-243.

BRASIL, Instituto Nacional de Câncer. ABC do câncer: abordagens básicas para o controle do câncer/Instituto Nacional do Câncer. Rio de Janeiro: INCA, 2011.

BRITTO, Lúcia Castro. A criança hospitalizada: relato de uma experiência. In: FILGUEIRAS, Maria Stella Tavares; RODRIGUES, Fernanda Deotti; BENFICA, Tânia Maria Silva (Org.). Psicologia hospitalar e da saúde: consolidando práticas e saberes na residência. $1^{\text {a }}$ ed. Petrópolis, RJ: Vozes, 2010. p. $27-52$.

CAVALCANTE, Ricardo Bezerra; CALIXTO, Pedro; PINHEIRO, Marta Macedo Kerr. Análise de Conteúdo: considerações gerais, relações com a pergunta pesquisa, possibilidades e limitações do método. Disponível em:

<www.ies.ufpb.br/ojs/index.php/ies/article/download-/10000/10871>

CARDOSO, Daniela Habekost et al. Cuidados paliativos na assistência hospitalar: a vivência de uma equipe multiprofissional. Texto Contexto Enfermagem, v.22, n.4, Florianópolis, 2013. Disponível em: <https://www.researchgate.net/profile/Isabel_Arrieira/publication/262628822_Hospice_care_in_a_hospital_setting_The_experience_of_a_multidisciplinary_tea $\mathrm{m} /$ links/53e9fbf50cf28f342f416be3.pdf>

CHIATTONE, Heloíza Benevides Carvalho. A criança e a morte. In: ANGERAMI-CAMON (org.). E a psicologia entro no hospital. 1ª ed. São Paulo: Cengage Learnig, 2012, p69-101.

COSTA, Francisca Flávia Loureiro. Câncer infantil: sentimentos, vivências e saberes do familiar cuidador. [Dissertação de mestrado], Campo Grande, MS, 2012. Disponível em: <http://site.ucdb.br/public/md-dissertacoes/13115-via-defesa.pdf>

DOMINGUES, Glaucia Regina et al. A atuação do psicólogo no tratamento de pacientes terminais e seus familiares. Psicologia Hospitalar, São Paulo, v.11, n¹, 2013. Disponível em: 〈http://pepsic.bvsalud.org/pdf/ph/v11n1/v11n1a02.pdf>

DUPAS, Giselle et al. Câncer na infância: conhecendo a experiência do pai. Revista Mineira de Enfermagem, v.16, n.3, 2012. Disponível em: 〈http://reme.org.br/artigo-/detalhes/537>

FAGUNDES, Celina Suely Oliveira et al. "Senti culpa, muita tristeza e vontade de chorar" Percepções sobre o câncer para mães e cuidadores de crianças em tratamento oncológico.

Revista Bionorte, v.4, n.2, 2015. Disponível em: <http://revistabionorte.com.br/arquivs_up/artigos/a15.pdf>

FARRINHAS, Giseli Vieceli; WENDLING, Maria Isabel; DELLAZZANA-ZANON, Letícia Lovato. Impacto psicológico do diagnóstico de câncer na família: um estudo de caso a partir 
da concepção do cuidador. Pensando Famílias, v.17, n.2, 2013. Disponível em: <http://pepsic.bvsalud.org/pdf/penf/v17n2/v17n2a09.pdf>

FERREIRA, Noeli Marchioro Liston et al. Câncer e família: compreendendo os significados simbólicos. Revista Ciência Cuidado e Saúde, v.9, n.2, 2010. Disponível em: < http://eduem.uem.br/ojs/index.php/CiencCuidSaude/article/viewFile/8749/6076>

FERREIRA, Vanessa dos Santos; RAMINELLI, Orilete. O olhar do paciente oncológico em relação a sua terminalidade: ponto de vista psicológico. Rev. SBPH, V.15, N.1, Rio de Janeiro, 2012. Disponível em: 〈http://pepsic.bvsalud.org/pdf/rsbph/v15n1/v15n1a07.pdf〉

FERSCH, Camila Fernanda de Moura et al. Estratégias de coping entre familiares de pacientes oncológicos. Revista Brasileira de Cancerologia, v.62, n.1, 2016. Disponível em: $<$ http://www.inca.gov.br/rbc/n_62/v01/pdf/04-artigo-estrategias-de-coping-entre-familiaresde-pacientes-oncologicos.pdf $>$

FREITAS, Gabrielle Silva de Souza; GOLÇALVES DE, Cíntia; MORAIS, Maria Izabel Dias Miorin de. A contribuição da fisioterapia nos cuidados paliativos em crianças com leucemia. Revista UNIABEU Belford Roxo, v.9, n.21, 2016. Disponível em: <http://www.uniabeu.edu.br/publica/index.php/RU/article/view/2161/pdf_315>

FORNAZARI, Silvia Aparecida; FERREIRA, Renata El Rafihi. Religiosidade/Espiritualidade em pacientes oncológicos: qualidade de vida e saúde. Psicologia: Teoria e Pesquisa, v.26, n.2, Brasília, 2010. Disponível em: 〈http://www.scielo.br/pdf/ptp/v26n2/a08v26n2.pdf〉.

HERMES, Hélida Ribeiro; LAMARCA, Isabel Cristina Arruda. Cuidados paliativos: uma abordagem a partir das categorias profissionais de saúde. Ciência \& saúde Coletiva, v.18, n.9, Rio de Janeiro, 2013. Disponível em: <http://www.scielo.br/pdf/csc/v18n9/v18n9a12.pdf>

HOSTERT, Paula Coimbra da Costa Pereira; ENUMO, Sônia Regina Fiorim; LOSS, Alessandra Brunoro Motta. Brincar e problemas de comportamento de crianças com câncer de classes hospitalares. Revista Psicologia: Teoria e Prática, v.16, n.1, São Paulo, 2014. Disponível em: < http://pepsic.bvsalud.org/pdf/ptp/v16n1/11.pdf >

HOSTERT, Paula Coimbra da Costa Pereira; MOTTA, Alessandra Brunoro; ENUMO, Sônia Regina Fiorim. Coping da hospitalização em crianças com câncer: a importância da classe hospitalar. Estudos de Psicologia, v.32, n.4, Campinas, 2015. Disponível em: <http://www.scielo.br/pdf/estpsi/v32n4/0103-166X-estpsi-32-04-00627.pdf>

GALVÃO, Tais Freire; PEREIRA, Mauricio Gomes. Revisão sistemática de literatura: passos para sua elaboração. Epidemiologia e Serviço de Saúde, n. 23, n.1, Brasília, 2014. Disponível em: 〈http://scielo.iec.pa.gov.br/pdf/ess/v23n1/v23n1a18.-pdf〉 
GUERRERO, Giselle Patrícia et al. Relação entre espiritualidade e câncer: perspectiva do paciente. Revista Brasileira de Enfermagem, v.64,n.1, Brasília, 2011. Disponível em: < http://www.scielo.br/pdf/reben/v64n1/v64n1a08.pdf>

GOBATTO, Caroline Amado; ARAUJO, Tereza Cristina Cavalcanti Ferreira de. Religiosidade e espiritualidade em oncologia: concepções de profissionais de saúde. Psicologia USP, v.24, n.1, São Paulo, 2013. Disponível em: <http://www.scielo-.br/pdf/pusp/v24n1/v24n1a02.pdf>

GOMES, Isabelle Pimentel, et al. Do diagnóstico à sobrevivência do câncer infantil: perspectiva de crianças. Texto Contexto Enferm., v.22, n.3, 2013. Disponível em: <http://www.scielo.br/pdf/tce/v22n3/v22n3a13.pdf>

GOMES, Isabelle sena; CAMINHA, Iraquitan de Oliveira. Guia para estudos de revisão sistemática: uma opção metodológica para as Ciências do Movimento Humano. Movimento, v.20, n.1, Porto Alegre, 2014. Disponível em: <http://www.seer.ufrgs.br/Movimento/article/viewFile/41542/28358>

GOMES, Gabriela Lisieux Lima; FERNANDES, Maria das Graças Melo; NÓBREGA, Maria Miriam Lima da. Ansiedade da hospitalização em crianças: análise conceitual. Revista Brasileira de Enfermagem, v.69, n.5, 2016. Disponível em: <http://www.scielo.br/pdf/reben/v69n5/0034-7167-reben-69-05-0940.pdf>

GUIMARÃES, Tuani Magalhães et al. Cuidados paliativos em oncologia pediátrica na percepção dos acadêmicos de enfermagem. Escola Anna Nery, v.20, n.2, 2016. Disponível em: 〈http://www.uniabeu.edu.br/publica/index.php/RU/article/view/2161/pdf_315>

GURGEL, Luciana Araújo; LAGE, Ana Maria Vieira. A atuação psicológica na assistência à crianças com câncer: da prevenção aos cuidados paliativos. Rev. de Psicologia, v.4, n.1, Fortaleza, 2013. Disponível em: <http://200.129.29.202/index.php/psicologiaufc/article/view/793/770>

KÜBLER-ROSS, Elisabeth. Sobre a morte e o morrer: o que os doentes terminais têm para ensinar a médicos, enfermeiras, religiosos e seus próprios parentes / Elisabeth Kübler-Ross; [tradução Paulo Menezes]. $9^{\mathrm{a}}$ ed. São Paulo: Editora WMF Martins Fontes, 2008.

LEVISK, Bárbara Luckow; LANGARO, Fabíola. O olhar humano sobre a vida: a consciência da finitude. Rev. SBPH, v.17, n.1, Rio de Janeiro, 2014. Disponível em: < http://pepsic.bvsalud.org/pdf/rsbph/v17n1/v17n1a04.pdf >

LIMA, Ana Sofia; BARROS, Luisa; ENUMO, Sônia Regina Fiorim. Enfrentamento em crianças portuguesas hospitalizadas por câncer: comparação de dois instrumentos de avaliação. Estudos de Psicologia, v.31, n.5, Campinas, 2014. Disponível em: < http://www.scielo.br/pdf/estpsi/v31n4/a10v31n4.pdf> 
MACIEIRA, Rita de Cassia; PALMA, Roseane Raffaini. Psico-oncologia e Cuidados paliativos. In: SANTOS, Franklin Santana (ed.). Cuidados Paliativos: diretrizes, humanização e alívio dos sintomas. $1^{\text {a }}$ ed. São Paulo: Editora Atheneu, 2011. p. 323-330.

MACIEL, Maria Goretti Sales. Definições e princípios. In: Cuidados Paliativos / Coordenação Institucional de Reinaldo Ayer de Oliveira. São Paulo: Conselho Regional de Medicina do Estado de São Paulo, 2008. Disponível em: <http://www.cremesp.org.br/library/modulos/publicacoes/pdf/livro_cuidado\%20paliativo.pdf $>$

MAGALHÃES, Suzane bandeira; FRANCO, Anamelia Lins e Silva. Experiência de profissionais e familiares de pacientes em cuidados paliativos. Arquivos Brasileiros de Psicologia, v.64, n.3, Rio de Janeiro, 2012. Disponível em: <http://pepsic.bvsalud.org/pdf/arbp/v64n3/v64n3a07.pdf >

MELO, Ana Georgia Cavalcanti de; CAPONERO, Ricardo. O futuro em cuidados paliativos. In: SANTOS, Franklin Santana (ed.). Cuidados Paliativos: diretrizes, humanização e alívio dos sintomas. $1^{\mathrm{a}}$ ed. São Paulo: Editora Atheneu, 2011. p.107-110.

MELO, Mônica Cristina Batista de et al. O funcionamento familiar do paciente com câncer. Psicologia em Revista, v.18, n.1, Belo Horizonte, 2012. Disponível em: <http://pepsic.bvsalud.org/pdf/per/v18n1/v18n1a07.pdf>

MENDES-CASTILLO, Ana Márcia Chiaradia, BOUSSO, Regina Szylit. A experiência das avós de crianças com câncer. Ver. Bras. Enferm., v.69, n.3, Brasília, 2016. Disponível em: <http://www.scielo.br/pdf/reben/v69n3/0034-7167-reben-69-03-0559.pdf>

MORAIS, Jamile Luz; CASTRO, Emily Suelen Antunes de; SOUZA, Airle Miranda de. A inserção do psicólogo na residência multiprofissional em saúde: um relato de experiência em psicologia. Psicologia em Revista, Belo Horizonte, v.18, n³, p.389-401, 2012. Disponível em: 〈http://pepsic.bvsalud.org/pdf/per/v18n3/v18n3a04.pdf>

MORAIS, Elissa Orlandi; ENUMO, Sônia Regina Fiorim. Estratégias de enfrentamento da hospitalização em crianças avaliadas por instrumento informatizado. Psico-USF, v.3, n.2, Itatiba, 2008. Disponível em: <http://www.scielo.br/pdf/pusf/v13n2/v13n2a09.pdf>.

${ }^{1}$ PONTE, Ana Carolina Silva L. C.; PAIS-RIBEIRO, José Luís. O bem-estar do doente seguido em cuidados paliativos (CP): comparação entre a perspectiva do doente e da família. Psicologia, Saúde \& Doença, v.15, n.1, 2014. Disponível em: < http://www.redalyc.org/pdf/362/36231157012.pdf>

2PONTE, Ana Carolina Silva L. C.; PAIS-RIBEIRO, José Luís. O bem-estar em cuidados paliativos: perspectiva do doente versus profissionais de saúde. Psicologia, Saúde \& Doença, v.15, n.1, 2014. Disponível em: 〈http://www.redalyc.org/pdf/362/36231157012.-pdf> 
PORTO, Gláucia; LUSTOSA, Maria Alice. Psicologia hospitalar e cuidados paliativos. Rev. SBPH, v.13, $\mathrm{n}^{\circ}$ 1, Rio de Janeiro, 2010. Disponível em: <http://pepsic.bvsalud.org/pdf/rsbph/v13n1/v13n1a07.pdf>

QUINTANA, Alberto Manuel et al. Lutos e lutas: reestruturações familiares diante do câncer em criança/adolescente. Psicol. Argum., v.29, n.65, 2011. Disponível em:

<http://webcache.googleusercontent.com/search?q=cache:MMU4oxXDPC4J:www2.pucpr.br/ reol/index.php/PA/pdf/\%3Fdd1\%3D4594+\&cd=1\&hl=pt-BR\&ct=clnk\&gl=br>

RECH, Bárbara Cristina Steffen; SILVA, Isabela Machado da; LOPES, Rita de Cássia Sobreira. Repercussões do câncer infantil sobre a relação conjugal. Psicologia: teoria e prática, v.29, n3, p.257-265, 2013. Disponível em: <http://www.scielo.br/pdf/ptp/v29n3/v29n3a03.pdf>

REIGADA, Carla et al. O suporte à família em cuidados paliativos. Textos \& Contextos, v.13, n.1, Porto Alegre, 2014. Disponível em: <https://repositorio-aberto.up.pt/bitstream/10216/74126/2/99887.pdf>

REZENDE, Adryene Milanez; SCHALL, Virgínia Torres; MODENA, Celina Maria. O câncer na adolescência vivenciando o diagnóstico. Psicologia: Teoria e Prática, v.13, n.3, 2011. Disponível em: 〈http://pepsic.bvsalud.org/pdf/ptp/v13n3-/v13n3a05.pdf>

REZENDE, Laura Cristina Silva; GOMES, Cristina Sansoni; MACHADO, Maria Eugenia da Costa. A finitude da vida e o papel do psicólogo: perspectiva em cuidados paliativos. Revista Psicologia e Saúde, v.6, n¹, p. 28-36, 2014. Disponível:

<http://pepsic.bvsalud.org/pdf/rpsaude/v6n1/v6n1a05.pdf>

ROLIM, Carmen Lucia Artioli. Entre escolas e hospitais: o desenvolvimento de criança em tratamento hospitalar. Pro-posições, v.26, n.3, p129-144, 2015. Disponível em: <http://www.scielo.br/pdf/pp/v26n3/0103-7307-pp-26-03-0129.pdf>

SAMAPAIO, Renato Tocantins; SAMPAIO, Ana Cristina Parente. Musicoterapia e cuidados paliativos: In: SANTOS, Franklin Santana. Cuidados paliativos: diretrizes, humanização e alívio dos sintomas. $1^{\mathrm{a}}$ ed. São Paulo: Editora Atheneu, 2011. p. 245-248.

SANTOS, Claudia Tavares dos; SABASTIANI, Ricardo Werner. Acompanhamento psicológico à pessoas portadoras de doenças crônicas. In: ANGERAMI-CAMON, Valdemar Augusto (Org.). E a psicologia entrou no hospital. $1^{\text {a }}$ ed. São Paulo: Cengage Learning, 2012. p. 147-175.

SANTOS, Franklin Santana. O desenvolvimento histórico dos cuidados paliativos e a filosofia hospice. In: (ed.). Cuidados Paliativos: diretrizes, humanização e alívio dos sintomas. $1^{\mathrm{a}}$ ed. São Paulo: Editora Atheneu, 2011, p.03-15.

SANTOS, Luiz Roberto Gonçalves dos; MENEZES, Mariana Pires; GRADVOHL, Silvia Mayumi Obana. Conhecimento, envolvimento e sentimentos de concluintes dos cursos de 
medicina, enfermagem e psicologia sobre ortotanásia. Ciência \& Saúde Coletiva, v.18, n.9, p.2645-2651, 2013. Disponível em: 〈http://www.scielo.br/pdf/csc/v18n9/v18n9a19.pdf〉

SANCHES, Mariana Vendrami Parra; NASCIMENTO, Lucila Castanheira; LIMA, Regina Aparecida Garcia. Crianças e adolescentes com câncer em cuidados paliativos: experiência de familiares. Revista Brasileira de Enfermagem, v.67, n.1, 2014. Disponível em: <http://www.scielo.br/pdf/reben/v67n1/0034-7167-reben-67-01-0028.pdf>

SCHLIEMANN, Ana Laura. Cuidados Paliativos e Psicologia: a construção de um espaço de trabalho. In: SANTOS, Franklin Santana (ed.). Cuidados Paliativos: diretrizes, humanização e alívio dos sintomas.1 $1^{\text {a }}$ ed. São Paulo: Editora Atheneu, 2011. p. 315-321.

SCHMIDHT, Beatriz; GABARRA, Lethícia Macedo; GONÇALVES, Janete Rodrigues. Intervenção psicológica em terminalidade e morte: relato de experiência. Paidéia, v.21, n.50, p.423-430, Ribeirão Preto, 2011. Disponível em: <http://www.scielo.br/pdf/paideia/v21n50/$15-. p d f>$

SCHNEIDER, Carine Marlene; MEDEIROS, Letícia Galery. Criança hospitalizada e o impacto emocional gerado nos pais. Unoesc \& Ciência - ACHS, v.2, n.2, Joaçaba, 2011. Disponível em: <http://editora.unoesc.edu.br/index.php/achs/article/view/741/pdf_216>

SILVA, Adriana Ferreira da et al. Cuidados paliativos em oncologia pediátrica: percepção, saberes e práticas na perspectiva da equipe multiprofissional. Revista Gaúcha de Enfermagem, v.36, n.2, Porto Alegre, 2015. Disponível em: < http://www.scielo.br/pdf/rgenf/-v36n2/pt_1983-1447-rgenf-36-02-00056.pdf >

SILVA, Georgia Sibele. Em busca de uma configuração do real. In: ANGERAMI-CAMON, Valdemar Augusto (Org.). E a psicologia entrou no hospital. $1^{\text {a }}$ ed. São Paulo: Cengage Learning, 2012. p.181-205.

SILVA, Lucelia Maria Lima da; MELO, Mônica Cristina Batista de; PEDROSA, Arli Diniz Oliveira Melo. A vivência do pai diante do câncer infantil. Psicologia em Estudo, v.18, n.3, Maringá, 2013. Disponível em: 〈http://www.scielo.br/pdf/pe/-v18n3/v18n3a14.pdf >

SILVA, Maria Raquel Bertioli da et al. O câncer entrou em meu lar: sentimentos expressos por familiares de clientes. Revista Enfermagem UEFJ, v.16, n.1, Rio de Janeiro, 2008. Disponível em: <http://www.revenf.bvs.br/pdf/reuerj/v16n1/v16-n1a11.pdf>

SILVA, Patricia Karla de Souza e; MELO, Symone Fernandes de. Experiência materna da perda de um filho com câncer infantil: um estudo fenomenológico. Revista da Abordagem Gestáltica, v.19, n.2, Goiânia, 2013. Disponível em: < http://pepsic.bvsalud.org/pdf/rag/v19n2/v19n2a02.pdf >

SILVEIRA, Maria Helena; CIAMPONE, Maria Helena Trench; GUTIERRREZ, Beatriz Aparecida Ozello. Percepção da equipe multiprofissional sobre cuidados paliativos. Revista 
Brasileira de Geriatria e Gerontologia, v.17, n.1, Rio de Janeiro, 2014. Disponível em: < http://www.scielo.br/pdf/rbgg/v17n1/1809-9823-rbgg-17-01-00007.pdf>

SIMONETTI, Alfredo. Manual de psicologia hospitalar: o mapa da doença. In: (org.). $6^{\text {a }}$ ed. São Paulo: Casa do Psicólogo, 2011. p. 13-32 115-143.

SIQUEIRA, Hilze Benigno de Oliveira Moura et al. Expressão da dor na criança com câncer: uma compreensão fenomenológica. Estudos de Psicologia, v.132, n.4, Campinas, 2015. Disponível em: 〈http://www.scielo.br/pdf/estpsi/v32n4/0103-166X-estpsi-32-04-00663.pdf>

SOUSA, Verônica de Moura et al. Espiritualidade, religiosidade e crenças pessoais de adolescentes com câncer. Revista Brasileira de Enfermagem, v.68, n.5, 2015. Disponível em: < http://www.scielo.br/pdf/reben/v68n5/0034-7167-reben-68-05-0791.pdf>

TOREZAN, Zeila Facci et al. A graduação em psicologia prepara para o trabalho no hospital? Psicologia: ciência e profissão, v.33, n.1, p132-145, Brasília, 2013. Disponível em: <http://www.scielo.br/pdf/pcp/v33n1/v33n1a11.pdf>

TORQUATO, Isolda Maria Barros et al. A doença e a hospitalização infantil: compreendendo o impacto na dinâmica familiar. Revista de Enfermagem UFPE online, v.6, n.11, 2012. Disponível em: < www.revista.ufpe.br/revistaenfermagem/index.php/revista/article/download-/.../4634>

VISONÁ, Fernanda; PREVEDELLO, Mariane; SOUZA, Emiliane Nogueira de. Câncer na família: percepções de familiares. Revista de Enfermagem da UFSM, v.2, n.1, 2012. Disponível em: < https://periodicos.ufsm.br/reufsm/article/view/3943/3148>

VIERO, Viviani. Prazer e sofrimento dos trabalhadores de enfermagem em oncologia pediátrica. [Dissertação] Santa Maria - RS, 2014. Disponível em:

<http://coral.ufsm.br/ppgenf/images/Mestrado/Dissertacoes/2014_2015/Dissertacao_Viviani_ Viero.pdf>

ZOMBINI, Edson Vanderlei et al. Classe Hospitalar: a articulação da saúde e educação como da política de humanização do SUS. Revista Trabalho, Educação e Saúde, v.10, n.1, Rio de Janeiro, 2012. Disponível em: <http://www.scielo.br/pdf/tes/v10n1/v10n1a05.pdf>

\section{Como citar este artigo (Formato ABNT):}

OLIVEIRA, Cibele B.; GRANGEIRO, Thércia, Grangeiro. Equipe Multiprofissional de Cuidados Paliativos da Oncologia Pediátrica: Uma Revisão Sistemática. Id on Line Revista Multidisciplinar e de Psicologia, Maio de 2017, vol.11, n.35, p. 492-530. ISSN: 1981-1179.

Recebido: 28.05.2017

Aceito: 29.05 .2017 